\title{
Recent advances in synthesis and applications of mixed matrix membranes
}

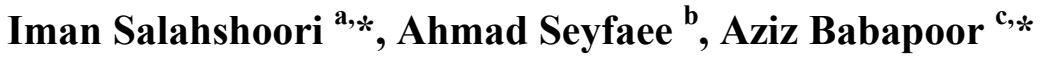 \\ ${ }^{a}$ Department of Chemical Engineering, Science and Research Branch, Islamic Azad University, Tehran, Iran \\ ${ }^{b}$ School of Mechanical Engineering, University of Adelaide, Adelaide, Australia \\ ${ }^{c}$ Department of Chemical Engineering, University of Mohaghegh Ardabili, Ardabil, Iran
}

\section{A B S T R A C T}

Researchers are currently considering membranes separation processes due to their ecofriendly, process simplicity and high efficiency. Selecting a suitable and efficient operation is the primary concern of researchers in the field of separation industries. In recent decades, polymeric and inorganic membranes in the separation industry have made significant progress. The polymeric and inorganic membranes have been challenged due to their competitiveness in permeability and selectivity factors. A combination of nanoparticle fillers within the polymer matrix is an effective method to increase polymeric and inorganic membranes' efficiency in separation processes. Mixed matrix membranes (MMMs) have been considered by the separation industry due to high mechanical and physicochemical, and transfer properties. Moreover, gas separation, oil treatment, heavy metal ions removal, water treatment and oilwater separation are common MMMs applications. Selecting suitable polymer blends and fillers is the key to the MMMs construction. The combination of rubbery and glassy polymers with close solubility parameters increases the MMMs performance. The filler type and synthesis methods also affect the morphological and transfer properties of MMMs significantly. Zeolites, graphene oxide (GO), nanosilica, carbon nanotubes (CNTs), zeolite imidazole frameworks (ZIFs) and metal-organic frameworks (MOFs) are used in the MMMs synthesis as fillers. Finally, solution mixing, polymerization in situ and sol-gel are the primary synthesising MMMs methods.

(C) 2021 The Authors. Published by Synsint Research Group.

\section{Introduction}

The advent of mixed matrix membranes (MMMs) has led to significant membrane performance advances [1]. The simultaneous increase in permeability, selectivity and physicochemical properties of the membrane are the main advantages of increasing the performance of MMMs compared to traditional membranes (polymeric and inorganic membranes) [2]. The advantages and disadvantages of polymeric, inorganic and mixed substrates are demonstrated in Fig. 1.
KEYWORDS

Separation process

Mixed matrix membranes

Nanofiller

Polymer blend

Synthesis

* Corresponding authors. E-mail addresses: iman.salahshoori@srbiau.ac.ir (I. Salahshoori), babapoor@uma.ac.ir (A. Babapoor).

Received 23 February 2021; Received in revised form 25 March 2021; Accepted 26 March 2021.

Peer review under responsibility of Synsint Research Group. This is an open access article under the CC BY license (https://creativecommons.org/licenses/by/4.0/). https://doi.org/10.53063/synsint.2021.116 


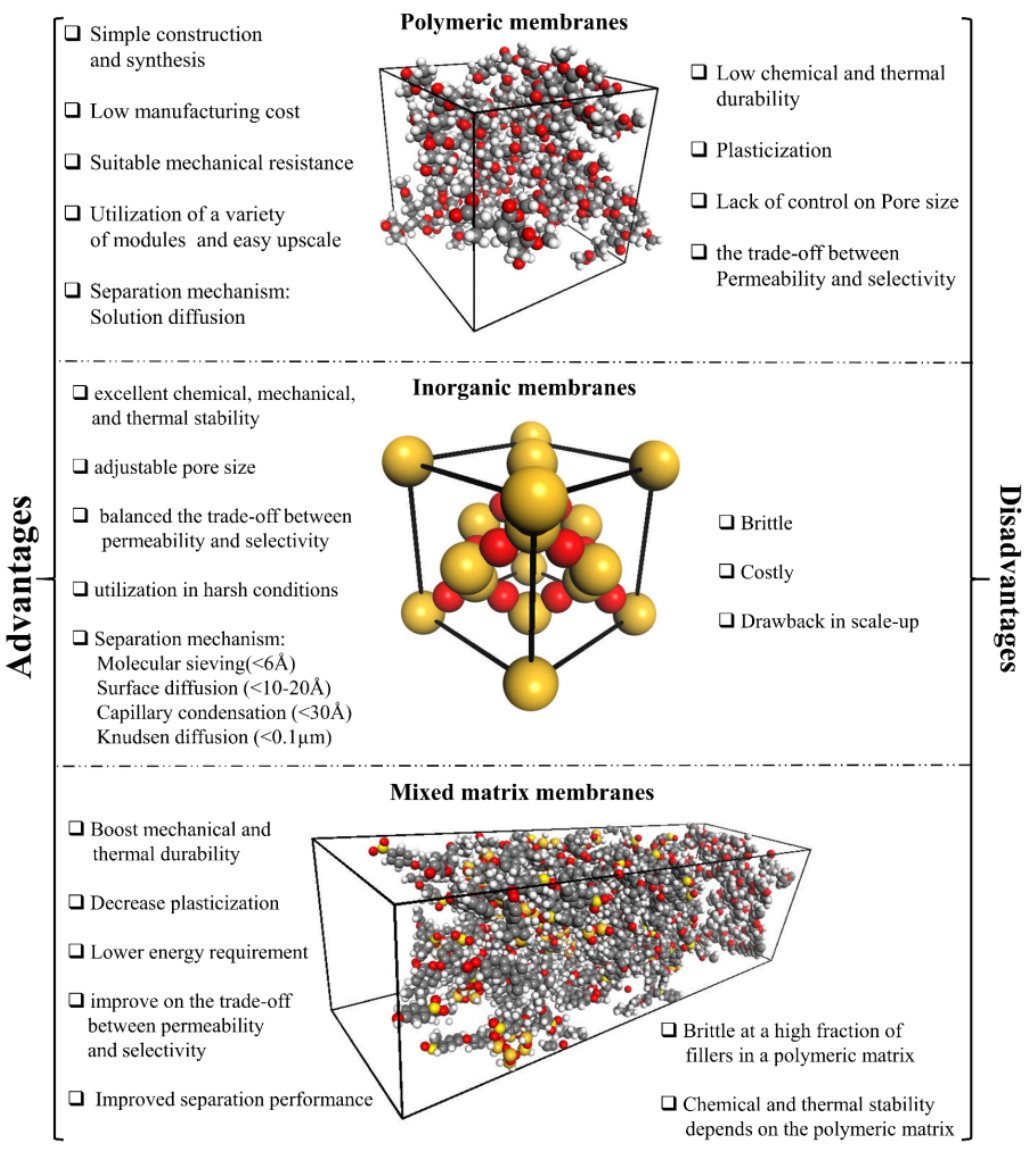

Fig. 1. Characteristics of different membranes (polymeric, inorganic and mixed matrix membranes).

The mixed matrix membranes construction has problems such as chemical structure control and surface chemistry that affect membrane performance [10]. It is usually challenging to construct ideally mixed matrix membranes due to the differences between the inorganic and

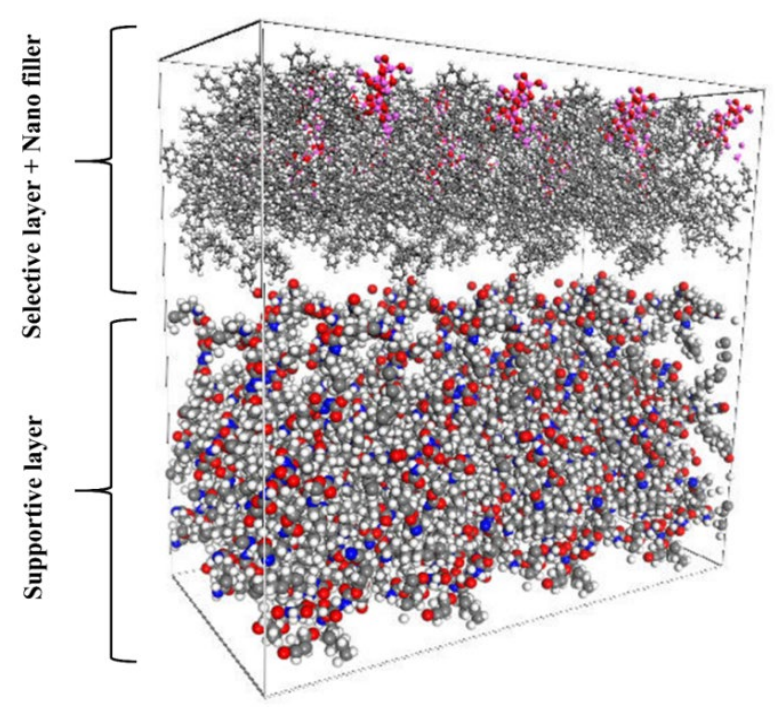

Fig. 2. Represents a schematic of the MMMs. polymer properties [11]. The filler's tendency to accumulate and the low compatibility between the polymer and the filler cause these defects in the two-phase interface. These defects, which significantly affect membrane performance, include interface void or sieve-in-acage, hardening of the polymer layer around the particles, and particle pore blockage [12]. For example, the accumulation of filler particles around each other and the need to break them for better membrane performance and the low tendency of glass polymers to inorganic fillers due to the low mobility of polymer chains mainly cause this complexity.

Synthesis methods and the type of filler used during synthesis are the keys to an ideal mixed matrix membranes success. Different synthesis methods and solutions have been used to create flawless and highperformance MMMs [5]. For example, various stirring methods (mechanical, ultrasound) are used to prevent particles' accumulation during polymer preparation [13]. Another way to improve a mixed matrix membranes performance and prevent surface imperfections is to reduce the $T_{g}$ polymer matrix by adding a softener to the membrane formulation. Blending polymers with different properties to construct a stable composition in physical and chemical properties is another way to improve mixed matrix membranes' performance. The key to this method's success is selecting polymers with close solubility parameters [14]. The type, physicochemical properties, structure, and surface chemistry of nanoparticles (fillers) significantly impact the performance of MMMs [11]. Some of the most used nanofillers are 
zeolites [15], graphene oxide (GO) [16, 17], nanosilica [18], carbon nanotubes (CNTs) [19, 20], natural clay attapulgite (ATP) [21], zeolite imidazole frameworks (ZIFs) [22], metal-organic frameworks (MOFs) [23], porous coordination polymers (PCPs) [24] and covalent organic frameworks (COFs) $[25,26]$. The selection of suitable solvents, the synthesis method and surface modification of these nanofillers are of special importance in improving mixed matrix membranes' performance. The present study's authors tried to overview the various synthesis methods and their advantages and disadvantages in constructing MMMs.

\section{Mixed matrix membranes application}

Mixed matrix membranes have a variety of applications in the separation industry. Recently, the gas separation industry using MMMs has made significant progress compared to traditional membranes [27]. On the one hand, despite their ease of use in gas separation, polymeric membranes have been challenged due to competitive conditions between permeability and selectivity. On the other hand, inorganic membranes, although they have high separation properties, the problematic conditions of formation and high manufacturing costs have created a significant challenge in their use [28]. The use of glassy and rubbery polymers and nanofillers simultaneously has increased mixed matrix membranes' performance under high temperature and pressure conditions in gas separation [29]. Mixed matrix membranes are widely used in the $\mathrm{CO}_{2}, \mathrm{CH}_{4}, \mathrm{~N}_{2}, \mathrm{H}_{2}, \mathrm{O}_{2}$ and $\mathrm{H}_{2} \mathrm{~S}$ gases separation. Research using mixed matrix membranes in the gas separation industry is reported in Table 1. Reverse osmosis, electrodialysis, ion exchange, chemical deposition, liquid-liquid extraction, emulsion liquid membrane, etc. are common techniques for removing heavy metals from sewage [30-33]. High energy consumption, high processing and operating costs, large production of liquid waste, and toxic sludge have created a significant challenge in using conventional methods [34]. Therefore, the mixed matrix membrane can have an actual application due to the low energy consumption process and materials with high absorption capacity and selectivity. Limited studies have been reported on removing heavy metals using mixed matrix membranes (Table 1). Production of liquid wastes due to high environmental pollution, phytoalexins release, and increased oxygen consumption are severe oil treatment problems. Significant disadvantages of traditional oil processing methods have led to the development of new techniques to improve performance in this area. Mixed matrix membranes have reduced the problems and weaknesses of conventional methods in the oil treatment industry [35].

Table 1. Mixed matrix membranes research in different application in the separation industry.

\begin{tabular}{|c|c|c|c|c|}
\hline \multicolumn{5}{|c|}{ Gas separation application } \\
\hline Polymer & Nanofiller & Gases & Description & Ref. \\
\hline Polysulfone (PSF) & Porphyrin & $\begin{array}{l}\text { - } \mathrm{CO}_{2} \\
\text { - } \mathrm{CH}_{4} \\
\text { - } \mathrm{N}_{2}\end{array}$ & $\begin{array}{l}\text { - Uniform distribution of nanofillers in the polymer structure } \\
\text { - Proper thermal stability } \\
\text { - Improving permeability and selectivity properties } \\
\text { - Improving permeability with increasing temperature }\end{array}$ & [36] \\
\hline Polyimide 6FDA-durene & UiO-66 & $\begin{array}{l}\text { - } \mathrm{CO}_{2} \\
\text { - } \mathrm{CH}_{4}\end{array}$ & $\begin{array}{l}\text { - Reducing the accumulation of nanofillers in the copolymer structure using } \\
\text { the } \mathrm{NH}_{2} \text { functional group } \\
\text { - Improving } \mathrm{CO}_{2} / \mathrm{CH}_{4} \text { separation performance }\end{array}$ & [37] \\
\hline Polysulfone (PSF) & $\begin{array}{l}\text { Iron pillared cloisite } 15 \mathrm{~A} \text { (P- } \\
\mathrm{C} 15 \mathrm{~A} \text { ) }\end{array}$ & $\begin{array}{l}\text { - } \mathrm{CO}_{2} \\
\text { - } \mathrm{N}_{2} \\
\text { - } \mathrm{O}_{2} \\
\end{array}$ & $\begin{array}{l}\text { - Proper dispersion of nanofillers in polymer matrix } \\
\text { - Increasing the permeability by increasing the number of nanofillers } \\
\text { - Reasonable performance of MMMs with Robson upper bond chart }\end{array}$ & [38] \\
\hline Matrimid & ZIF-68, 69 and 78 & $\begin{array}{l}\text { - } \mathrm{CO}_{2} \\
\text { - } \mathrm{CH}_{4} \\
\text { - } \mathrm{N}_{2} \\
\end{array}$ & $\begin{array}{l}\text { - The maximum increase in } \mathrm{CO}_{2} \text { permeability using } \mathrm{ZIF}-68 \\
\text { - Increasing the selectivity of } \mathrm{CO}_{2} / \mathrm{N}_{2} \text { and } \mathrm{CO}_{2} / \mathrm{CH}_{4} \text { using } 20 \% \text { ZIF- } 68\end{array}$ & [39] \\
\hline $\begin{array}{l}\text { Polysulfone/polyethylene } \\
\text { glycol (PSF/PEG) }\end{array}$ & Graphene hydroxyl & $\begin{array}{l}-\mathrm{CO}_{2} \\
\text { - } \mathrm{CH}_{4} \\
\end{array}$ & $\begin{array}{l}\text { - Proper distribution of nanoparticles in the polymer matrix } \\
\text { - Increasing the permeability of } \mathrm{CO}_{2} \\
\text { - Improving the selectivity properties by increasing the nanoparticles }\end{array}$ & [40] \\
\hline Polyurethane & Zeolite $3 \mathrm{~A}$ and $\mathrm{ZSM}-5$ & $\begin{array}{l}\text { - } \mathrm{CO}_{2} \\
\text { - } \mathrm{CH}_{4} \\
\text { - } \mathrm{N}_{2} \\
\text { - } \mathrm{O}_{2}\end{array}$ & $\begin{array}{l}\text { - Using central composite design for optimization } \\
\text { - Optimization of permeability at } 18 \mathrm{wt} \% \text { nanoparticle concentration, } \\
\text { temperature } 30^{\circ} \mathrm{C} \text { and } 0.8 \mathrm{MPa} \text { pressure } \\
\text { - Optimization of selectivity at } 5.8 \mathrm{wt} \% \text { nanoparticle concentration, } \\
\text { temperature } 22.5^{\circ} \mathrm{C} \text { and } 2.5 \mathrm{MPa} \text { pressure }\end{array}$ & [41] \\
\hline Pebax-1657 & MIL-101 and $\mathrm{NH}_{2}$-MIL-101 & $\begin{array}{l}-\mathrm{CO}_{2} \\
\text { - } \mathrm{N}_{2}\end{array}$ & $\begin{array}{l}\text { - The successful synthesis of MIL-101 and } \mathrm{NH}_{2} \text {-MIL- } 101 \text { polymer matrix } \\
\text { - Improving selectivity properties at }-20{ }^{\circ} \mathrm{C} \text { compared to ambient } \\
\text { temperature }\end{array}$ & [42] \\
\hline Pebax 1657/PES & ZIF-8 & $\begin{array}{l}\text { - } \mathrm{CO}_{2} \\
\text { - } \mathrm{CH}_{4}\end{array}$ & - Improving $\mathrm{CO}_{2}$ permeability and $\mathrm{CO}_{2} / \mathrm{CH}_{4}$ selectivity & [43] \\
\hline
\end{tabular}


Table 1. Continued.

\begin{tabular}{|c|c|c|c|c|c|}
\hline Polymer & Nanofiller & Gases & & Description & Ref. \\
\hline $\begin{array}{l}\text { Polyether block amide } \\
\text { (PEBAX-5513) }\end{array}$ & $\begin{array}{l}\text { Potassium tetrafluorobo } \\
\text { (KBF4) }\end{array}$ & rate $\mathrm{CO}_{2}$ & & - Improving $\mathrm{CO}_{2}$ permeability & {$[44]$} \\
\hline Polyurethane & $\mathrm{SiO}_{2}, \mathrm{ZSM}-5$, and ZIF- 8 & $\begin{array}{ll} & \mathrm{CO}_{2} \\
\text { - } \mathrm{CH}_{4}\end{array}$ & & - Best separation performance with ZIF-8 nanofillers & {$[45]$} \\
\hline \multicolumn{6}{|c|}{ Removal of heavy metal ions } \\
\hline Polymer & Nanofiller & \multicolumn{2}{|l|}{ Metals ion } & Description & Ref. \\
\hline $\begin{array}{l}\text { Polysulfone (PSF) and } \\
\text { polyethylene glycol (PEG) }\end{array}$ & Graphene oxide (GO) & \multicolumn{3}{|c|}{ 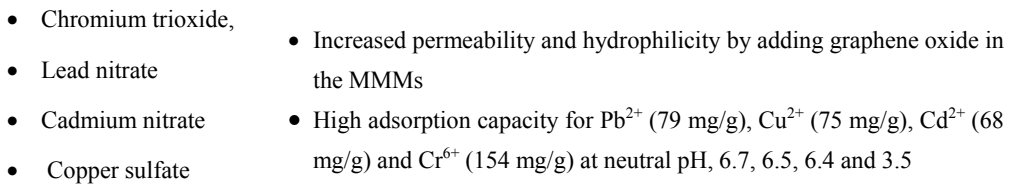 } & {$[34]$} \\
\hline $\begin{array}{l}\text { Polyvinylidene fluoride } \\
\text { (PVDF) and polyvinyl } \\
\text { pyrrolidone (PVP) }\end{array}$ & $\begin{array}{l}\alpha \text {-zirconium phosphate } \\
(\alpha \text {-ZrP })\end{array}$ & \multicolumn{2}{|c|}{$\begin{aligned} & \mathrm{Cu}\left(\mathrm{NO}_{3}\right)_{2}, 3 \mathrm{H}_{2} \mathrm{O}, \\
&\left(\mathrm{Cu}^{2+}\right) \\
& \text { - } \mathrm{ZnCl}_{2}, \\
& \text { - } \mathrm{NiCl}_{2}, 6 \mathrm{H}_{2} \mathrm{O},\left(\mathrm{Ni}^{2+}\right) \\
& \text { - } \mathrm{Pb}\left(\mathrm{NO}_{3}\right)_{2},\left(\mathrm{~Pb}^{2+}\right) \\
& \text { - } \mathrm{Cd} \quad\left(\mathrm{NO}_{3}\right)_{2}, 4 \mathrm{H}_{2} \mathrm{O} \\
&\left(\mathrm{Cd}^{2+}\right) \\
&\end{aligned}$} & $\begin{array}{l}\text { - } 42.8 \%\left(\mathrm{Cd}^{2+}\right), 93.1 \%\left(\mathrm{Cu}^{2+}\right), 44.4 \%\left(\mathrm{Ni}^{2+}\right), 91.2 \%\left(\mathrm{~Pb}^{2+}\right), \text { and } 44.2 \% \\
\left(\mathrm{Zn}^{2+}\right) \text { were removed from an aqueous solution at neutral } \mathrm{pH} \text { during } \\
\text { filtration using MMMs }\end{array}$ & {$[7]$} \\
\hline $\begin{array}{l}\text { Polyacrylic acid (PAA) } \\
\text { polyvinylidene fluoride } \\
(\mathrm{PVDF})\end{array}$ & $\begin{array}{l}\text { Immobilizing zeolitic } \\
\text { imidazolate framework- } \\
8 \text { (ZIF-8) }\end{array}$ & \multicolumn{2}{|l|}{$\begin{array}{l}\text { - Nickel } \\
\mathrm{Ni}\left(\mathrm{NO}_{3}\right)_{2}\end{array}$} & $\begin{array}{l}\text { - Relatively high-water flux of } 460 \mathrm{~L} \cdot \mathrm{m}^{-2} \mathrm{~h}^{-1} \\
\text { - Nickel ion }(\mathrm{Ni}(\mathrm{II})) \text { capacity }(219.09 \mathrm{mg} / \mathrm{g}) \text { from a synthetic high- } \\
\text { salinity }\left(\left[\mathrm{Na}^{+}\right]=15000 \mathrm{mg} / \mathrm{L}\right) \text { wastewater }\end{array}$ & {$[46]$} \\
\hline Polyethersulfone (PES) & Graphene oxide (GO) & \multicolumn{2}{|l|}{$\begin{array}{l}\text { - } \mathrm{MgSO}_{4} \\
\mathrm{Na}_{2} \mathrm{SO}_{4}\end{array}$} & $\begin{array}{l}\text { - Reduce the contact angle between the water droplet and the surface } \\
\text { and increase the membrane hydrophilicity } \\
\text { - Improving the separation of heavy metals by adding graphene oxide }\end{array}$ & {$[47]$} \\
\hline Polysulfone (PSF) & Zeolite nanoparticles & \multicolumn{2}{|l|}{$\begin{array}{l}\text { - Lead } \\
\text { - Nickel }\end{array}$} & $\begin{array}{l}\text { - Improving water absorption capacity and hydraulic permeability } \\
\text { - Lead and nickel ions showed adsorption capacities of } 682 \text { and } 122 \\
\mathrm{mg} / \mathrm{g} \text { in the membrane, respectively }\end{array}$ & {$[48]$} \\
\hline \multicolumn{6}{|l|}{ Oil treatment } \\
\hline Polymer & Nanofiller & Oil & \multicolumn{2}{|c|}{ Description } & Ref. \\
\hline $\begin{array}{l}\text { Polyethersulfones (PES) } \\
\text { and polyvinylpyrrolidone } \\
(\mathrm{PVP})\end{array}$ & $\begin{array}{l}\text { Functionalized carbon } \\
\text { nanotube (F-MWCNT) }\end{array}$ & $\begin{array}{l}- \text { Olive } \\
\text { oil }\end{array}$ & \multicolumn{2}{|c|}{$\begin{array}{l}\text { - Optimal conditions include penetration flux } 21.2\left(\mathrm{~kg} / \mathrm{m}^{2}\right) \text {, flux reduction } 12.6 \% \text {, } \\
\text { COD removal } 72.6 \% \text { and total phenol rejection } 89.5 \%\end{array}$} & [35] \\
\hline $\begin{array}{l}\text { Polyvinylidene fluoride } \\
\text { (PVDF) }\end{array}$ & $\begin{array}{l}\text { Graphene oxide }(\mathrm{GO}) \\
\text { and oxidized multi- } \\
\text { walled carbon nanotubes } \\
\text { (OMWCNTs) }\end{array}$ & $\begin{array}{l}\text { - Palm } \\
\text { oil }\end{array}$ & \multicolumn{2}{|c|}{$\begin{array}{l}\text { - Proper distribution of nanoparticles in the polymer matrix and successful synthesis } \\
\text { - Improving the performance of MMMs in comparison with other membranes } \\
\text { - Increasing anti-contamination due to nanoparticle deposition and increasing } \\
\text { membrane humidity }\end{array}$} & {$[49]$} \\
\hline Polycarbonate & $\begin{array}{l}\text { Modified halloysite } \\
\text { nanotubes and Graphene } \\
\text { oxide nanosheets }\end{array}$ & $\begin{array}{l}- \text { Olive } \\
\text { oil }\end{array}$ & \multicolumn{2}{|c|}{$\begin{array}{l}\text { - Improvement of hydrophilicity and higher pure water flux due to the presence of } \\
\text { amphiphilic sodium dodecyl sulfate surfactant in membranes containing modified } \\
\text { halloysite nanotubes } \\
\text { - } 100 \% \text { olive oil recovery efficiency }\end{array}$} & {$[50]$} \\
\hline $\begin{array}{l}\text { Polysulfone (PS) and } \\
\text { polyvinylpyrrolidone } \\
(\mathrm{PVP})\end{array}$ & $\begin{array}{l}\text { Aspartic acid (AA) } \\
\text { functionalized graphene } \\
\text { oxide (fGO) }\end{array}$ & - Oil & \multicolumn{2}{|c|}{$\begin{array}{l}\text { - Improved membrane permeability due to reduced contact angle measurement and } \\
\text { increased hydrophilicity } \\
\text { - Increasing Young's modulus }\end{array}$} & {$[51]$} \\
\hline Polybenzimidazole (PBI) & Graphene oxide (GO) & - Oil & \multicolumn{2}{|c|}{$\begin{array}{l}\text { - Improves membrane performance with high oil removal efficiency } \\
\text { - Increasing the hydrophilic nature of the membrane and its anti-moisture properties }\end{array}$} & {$[52]$} \\
\hline
\end{tabular}

\section{Mixed matrix membrane synthesis and challenges}

\subsection{Morphological analysis}

The mixed matrix membranes construction is associated with several problems, including low interaction between the nanofiller and the polymer matrix and the heterogeneous distribution of filler particles within the continuous polymer phase. Moreover, particle size, particle pore size, dispersed phase volume percentage, and the chemical properties of polymers are other challenging factors in mixed matrix membranes synthesis $[10,53]$.

The type of compounds, synthesis and dispersion of the polymer matrix filler phase are essential keys to constructing a flawless mixed matrix 
membrane. The polymer and the filler are bonded together by covalent and van der Waals bonds [54]. Fourier-transform infrared spectroscopy (FTIR), X-ray powder diffraction (XRD), scanning electron microscopy (SEM), Thermogravimetric analysis (TGA) and differential scanning calorimetry (DSC) tests are the most used tests to evaluate the structure and performance of mixed matrix membranes. Determining bond type- connecting filler with continuous phase and chemical interaction between polymer and nanofiller in the mixed matrix membrane- is one FTIR test application. The absorption of infrared radiation, like other absorption processes, is a quantum process. In this way, only specific frequencies of infrared radiation are absorbed by the molecule and cause tensile and flexural vibration of covalent bonds. The energy absorbed from infrared light by chemical bonds with specific functional groups at specified wavelengths leads to a decrease in light transmission intensity, which is usually plotted as a function of the wavenumber (in $\mathrm{cm}$ ) [55]. Meshkat et al. used FTIR analysis to evaluate the Pebax-MIL-53 mixed matrix membranes bonds and membrane structures [56].

$\mathrm{X}$-ray diffraction determines the mixed matrix membrane state in terms of crystalline and amorphous structure. Moreover, XRD is a widely used technique in investigating the characteristics of the sample and the generality of crystalline structure properties such as network constant, network geometry, qualitative determination of unidentified materials, crystal phase and size determination, the orientation of single crystals, network defects, etc. It should be noted that the membrane with the crystalline state has higher intensity peaks, while with the increasing amorphous state, the intensity of X-diffraction pattern peaks decreases. The amorphous and crystalline state of the membrane significantly affects the degree of permeability and selectivity [3, 57]. For example, Kim et al. [58] Investigated the fabrication of a mixed matrix membrane by adding $\mathrm{TiO} 2$ and fly ash nanoparticles (FA) to the polymer structure for water treatment. The presence of $\mathrm{TiO} 2$ nanoparticles in the polymer matrix at the peaks of FA and $\mathrm{TiO} 2$ is clearly seen in the TiO2-FA/PU membrane. Evaluation of glass transition temperature and membrane heat resistance are respectively essential DSC and TGA tests applications [59].

Investigating the distribution of filler particles in the membrane matrix and calculating the membrane thickness are critical SEM analysis applications $[1,60]$. It should be noted that the type of solvent used and the synthesis method are very useful in the morphological process of membranes [61].

Apart from the SEM test, Field Emission Scanning Electron Microscope (FESEM) and transmission electron microscopy (TEM) tests are essential and widely used methods to determine nanoparticles distribution in the polymer matrix and determine particle agglomeration phenomenon. SEM and FESEM analyses are used to see images from the sample surface. The difference is that FESEM has a higher image resolution and is used to observe the interface between particles and polymers, especially in glassy polymers. TEM analysis can show an accurate particle scattering pattern within the polymer matrix with full resolution.

\subsection{Synthesis methods}

In addition to selecting membrane components, synthesis methods are also crucial in constructing a mixed matrix membrane without defects.
The polymer blends with different properties are currently a crucial factor in mixed matrix membranes' success. Various factors play a significant role in the synthesis of polymers, such as the type of the polymer in terms of being rubbery and glassy, the solubility parameter, the solvent consumption and the desired temperature [62, 63]. Proper distribution of filler particles within the polymer matrix is another critical point in the fabrication of a mixed matrix membrane that directly affects the interface between the polymer and the filler. Low interaction between the filler and the polymer creates undesirable channels that allow the molecules to pass through with the least mass transfer resistance on their path and reduce membrane performance [53]. In this section, different synthesis methods related to polymeric composition and fillers are investigated.

\subsubsection{Blend polymer}

Scientists have considered industrial polymers synthesis to develop a new structure to improve single polymers properties. Selecting suitable polymers with close solubility parameters (polymer structure and suitable chemical properties), choosing a suitable solvent (as a reaction environment for raw polymers), appropriate reaction environment, adding stabilizers and adding a copolymer are some of the most influential parameters in the process of making a polymer blend [64]. In recent decades, many polymers with different structures have been produced and used in a variety of applications. However, the rapid advancement of technology in multiple fields has created many applications. Therefore, there is an increasing need for the production of polymers with specific properties. In this regard, researchers have used many methods, the most important of which are copolymerization and blending. The blending method has a special place among the various forms due to features such as flexibility in material selection, design properties of the final product, and economy [65, 66]. Morphological control is an essential aspect of polymer blends due to the control of rheological behavior, processability, and compounds' physical and mechanical properties. It is complicated to stabilize polymer blends' morphology to achieve the desired properties due to the lack of suitable compatibility in the molecular structure in terms of rheological thermodynamic properties [67]. The polymer blend is a mixture consisting of at least two polymers or two copolymers divided into two categories: miscible polymer blends (It is a polymer mixture that is homogeneous on the molecular scale and its free mixing energy negative $(\Delta \mathrm{G}<0)$ and Immiscible polymer blend (Polymer blend with free mixing positive energy $\left(\Delta \mathrm{G}_{\mathrm{m}}>0\right)[68,69]$. Miscibility means forming a phase of a mixture including several components in a specific range of temperature, pressure and composition. The number of miscible and immiscible polymers with glass transition temperature and their solubility parameters are reported in Table 2 .

Size, shape, and distribution of one phase in another phase in immiscible polymers depend on parameters such as the percentage of the mixture, the ratio of viscosities, the ratio of elasticity, the surface tension, as well as the process conditions such as temperature, time, and mixing intensity. In general, polymer blends can be divided into two main categories: polymer blend containing a dispersed phase (such as droplets in a matrix) and co-continuous morphology [70, 71]. Mechanical blending, solution blending, reactive blending and latex blending are common methods of making polymer blends. 
Table 2. Some reported miscible and immiscible polymer blend system with solubility parameter, glass transition temperature and 3D-structure.

\begin{tabular}{|c|c|c|c|c|c|c|}
\hline Polymer blend & Structure & Formula & Component, \% & $\mathbf{T}_{\mathrm{g}}$ value & $\begin{array}{l}\text { Solubility } \\
\text { parameter }\end{array}$ & Ref. \\
\hline \multicolumn{7}{|l|}{ Miscible polymer blend } \\
\hline Polybutylene & & $\left(\mathrm{C}_{4} \mathrm{H}_{8}\right)_{\mathrm{n}}$ & 25 & $-100{ }^{\circ} \mathrm{C}$ & $15.5-16.4 \mathrm{MPa}^{1 / 2}$ & \multirow{2}{*}{ [72] } \\
\hline Styrene-butadiene & & $\mathrm{C}_{12} \mathrm{H}_{14}$ & 75 & $-15^{\circ} \mathrm{C}$ & $17-19 \mathrm{MPa}^{1 / 2}$ & \\
\hline Polybutylene terephthalate & & $\left(\mathrm{C}_{10} \mathrm{H}_{8} \mathrm{O}_{4}\right)_{\mathrm{n}}$ & 25 & $40{ }^{\circ} \mathrm{C}$ & $22.4 \mathrm{MPa}^{1 / 2}$ & \multirow{2}{*}{ [73] } \\
\hline Polyethylene terephthalate & & $\left(\mathrm{C}_{12} \mathrm{H}_{12} \mathrm{O}_{4}\right)_{\mathrm{n}}$ & 75 & $81^{\circ} \mathrm{C}$ & $17.8-24.8 \mathrm{MPa}^{1 / 2}$ & \\
\hline $\begin{array}{l}\text { Polyvinylidene difluoride } \\
\text { (PVDF) }\end{array}$ & & $-\left(\mathrm{C}_{2} \mathrm{H}_{2} \mathrm{~F}_{2}\right)_{\mathrm{n}^{-}}$ & 25 & $-40^{\circ} \mathrm{C}$ & $16.8-18.4 \mathrm{MPa}^{1 / 2}$ & \\
\hline Polymethyl acrylate (PMA) & & $\left(\mathrm{C}_{4} \mathrm{H}_{6} \mathrm{O}_{2}\right)_{\mathrm{n}}$ & 75 & $16^{\circ} \mathrm{C}$ & $18.2-21.3 \mathrm{MPa}^{1 / 2}$ & \\
\hline Polystyrene (PS) & & $\left(\mathrm{C}_{8} \mathrm{H}_{8}\right)_{\mathrm{n}}$ & 20 & $96{ }^{\circ} \mathrm{C}$ & $18.3 \mathrm{MPa}^{1 / 2}$ & \\
\hline \multicolumn{7}{|l|}{ Poly (p-phenylene oxide) } \\
\hline & & $\left(\mathrm{C}_{8} \mathrm{H}_{8} \mathrm{O}\right)_{\mathrm{n}}$ & 80 & $216^{\circ} \mathrm{C}$ & $20.8-21.6 \mathrm{MPa}^{1 / 2}$ & \\
\hline $\begin{array}{l}\text { Acrylonitrile butadiene } \\
\text { styrene (ABS) }\end{array}$ & & $\left(\mathrm{C}_{8} \mathrm{H}_{8} \cdot \mathrm{C}_{4} \mathrm{H}_{6} \cdot \mathrm{C}_{3} \mathrm{H}_{3} \mathrm{~N}\right)_{\mathrm{n}}$ & 30 & $105^{\circ} \mathrm{C}$ & $\mathrm{N} / \mathrm{A}$ & \multirow{2}{*}{ [76] } \\
\hline Poly (L-lactide) (PLLA) & & $\left(\mathrm{C}_{3} \mathrm{H}_{4} \mathrm{O}_{2}\right)_{\mathrm{n}}$ & 70 & $60{ }^{\circ} \mathrm{C}$ & $19.2-21.1 \mathrm{MPa}^{1 / 2}$ & \\
\hline \multicolumn{7}{|l|}{ Immiscible polymer blend } \\
\hline Polystyrene (PS) & & $\left(\mathrm{C}_{8} \mathrm{H}_{8}\right)_{\mathrm{n}}$ & 30 & $96^{\circ} \mathrm{C}$ & $18.3 \mathrm{MPa}^{1 / 2}$ & \multirow{4}{*}{ [77] } \\
\hline Polybutadiene (PB) & & $\left(\mathrm{CH}_{2} \mathrm{CH}=\mathrm{CHCH}_{2}\right)_{\mathrm{n}}$ & 70 & $-100^{\circ} \mathrm{C}$ & $17.0 \mathrm{MPa}^{1 / 2}$ & \\
\hline Nylon 6 & & $\left(\mathrm{C}_{6} \mathrm{H}_{11} \mathrm{NO}\right)_{\mathrm{n}}$ & 20 & $54^{\circ} \mathrm{C}$ & $21.5-32.0 \mathrm{MPa}^{1 / 2}$ & \\
\hline Nylon 612 & 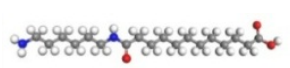 & $\mathrm{C}_{18} \mathrm{H}_{36} \mathrm{~N}_{2} \mathrm{O}_{3}$ & 80 & $46{ }^{\circ} \mathrm{C}$ & $21.5-23.3 \mathrm{MPa}^{1 / 2}$ & \\
\hline
\end{tabular}


Table 2. Continued.

\begin{tabular}{|c|c|c|c|c|c|c|}
\hline Polymer blend & Structure & Formula & Component, \% & $\mathbf{T}_{\mathrm{g}}$ value & $\begin{array}{l}\text { Solubility } \\
\text { parameter }\end{array}$ & Ref. \\
\hline $\begin{array}{l}\text { Polyethylene terephthalate } \\
\qquad(\mathrm{PET})\end{array}$ & & $\left(\mathrm{C}_{12} \mathrm{H}_{12} \mathrm{O}_{4}\right)_{\mathrm{n}}$ & 20 & $81^{\circ} \mathrm{C}$ & $17.8-24.8 \mathrm{MPa}^{1 / 2}$ & \multirow{2}{*}{ [79] } \\
\hline Polycarbonates (PC) & & $\mathrm{C}_{15} \mathrm{H}_{16} \mathrm{O}_{2}$ & 80 & $149^{\circ} \mathrm{C}$ & $17.95 \mathrm{MPa}^{1 / 2}$ & \\
\hline Polystyrene (PS) & & $\left(\mathrm{C}_{8} \mathrm{H}_{8}\right)_{\mathrm{n}}$ & 20 & $96^{\circ} \mathrm{C}$ & $18.3 \mathrm{MPa}^{1 / 2}$ & \multirow{2}{*}[80]{} \\
\hline Polycarbonates (PC) & & $\mathrm{C}_{15} \mathrm{H}_{16} \mathrm{O}_{2}$ & 80 & $149^{\circ} \mathrm{C}$ & $17.95 \mathrm{MPa}^{1 / 2}$ & \\
\hline
\end{tabular}

\subsubsection{Mechanical (melting) blending}

The most straightforward commercial and non-contaminating techniques to produce polymer blends are using a mechanical blending process [81]. In the industrial method of mechanical blending, a single screw extruder is used, which is one of the advantages of this method: the continuous movement of the screw and production in a suitable form for further processing. The low penetration rate of polymers due to their high molecular weight slows down the mixing process and prolongs the melt mixing time due to the low thermal stability of some polymers, causing problems. Placing the raw materials in a special chamber and increasing the temperature to create a uniform mixture is one of the main steps in making a polymer composition. It should be noted that temperature, pressure and process time are determining factors in this method. The two-screw extruder is used to increase shearing forces and improve mixing (Fig. 3). In mechanical mixing, the mixture properties are affected by the mixer's speed, the mixing temperature of the components and the mixing time [82].

\subsubsection{Solution blending}

The production of a thin film by dissolving two polymers in a common solvent and then evaporating the solvent is known as the solution blending method. If fuzzy separation occurs in the solvent presence, the two polymers become immiscible as a result of uniform mixture is not obtained. Evaporation of the solvent will also be problematic to produce thicker films. This method is used to produce polymer films and membranes that are used for commercial applications. The conventional techniques of stirring two polymers are shorn mixing,

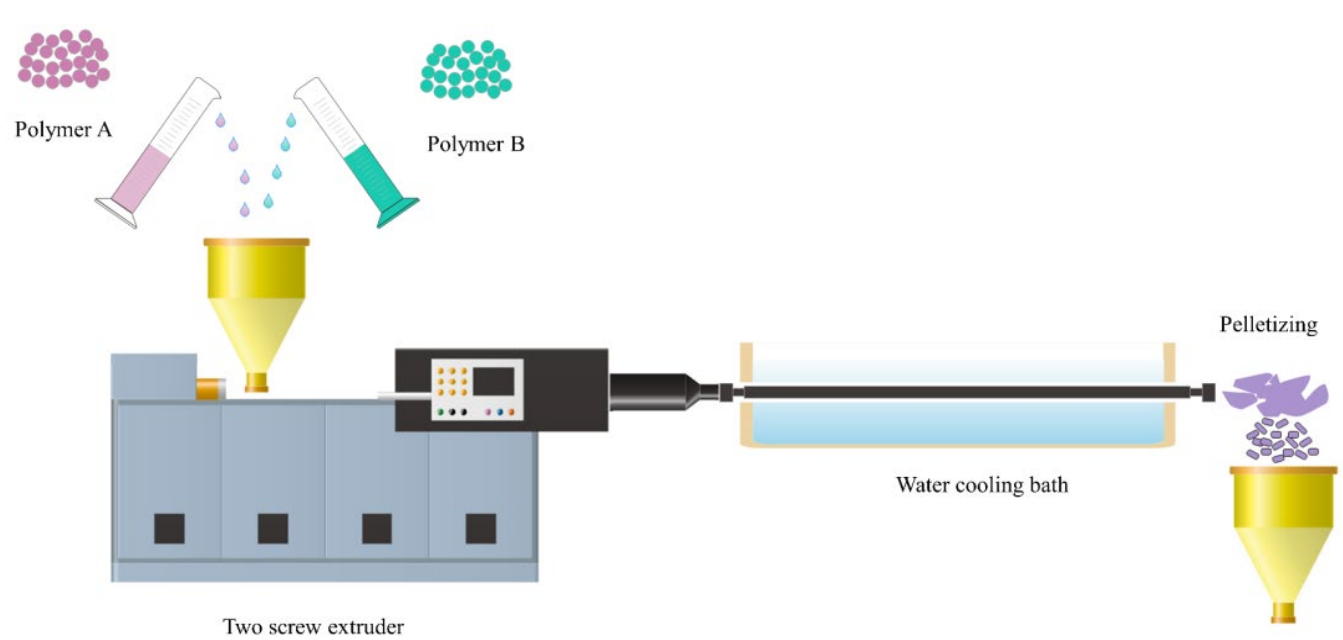

Fig. 3. The schematic of two screw extruders for mechanical blending. 


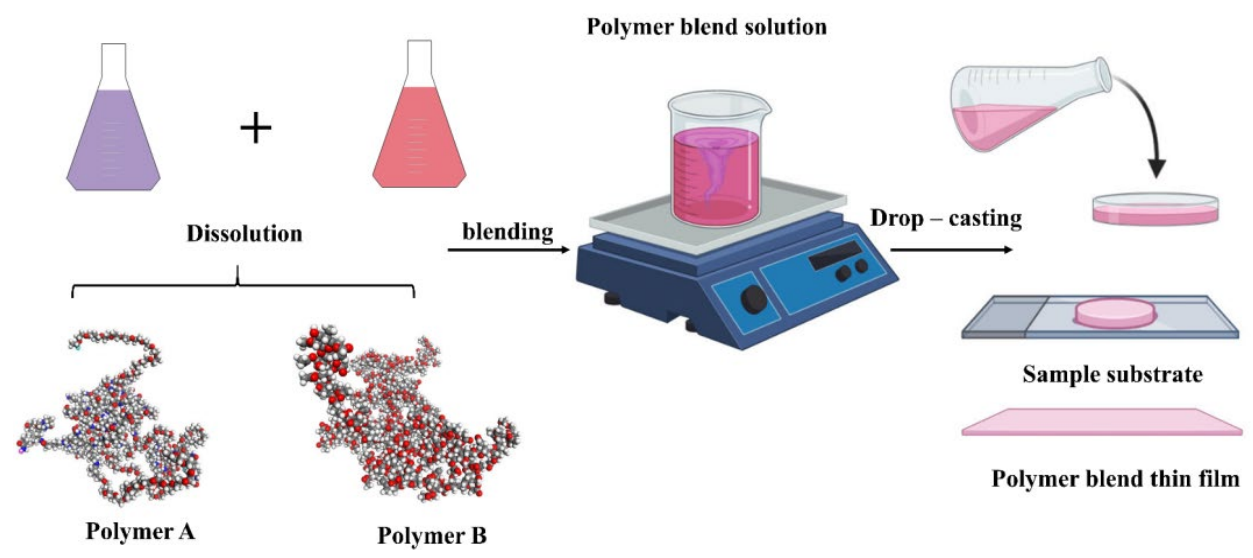

Fig. 4. A general schematic of making a polymer blend using the blending solution method.

magnetic stirring and reflux methods [83]. The essential steps to perform this method are summarized as follows [84]:

- Proper selection of polymer compounds

- Select a suitable solvent for the dissolution process

- Homogeneity process in a specified time

- Add binders and compatibilizers

- Casting process

A General schematic of making a polymer blend using the blending solution method is shown in Fig. 4.

\subsubsection{Freeze drying}

Freeze-drying is one method of making polymer blending in which the polymer components are placed in a very low temperature and frozen solution. In this method, polymers are rarely agglomerated, and all frozen solvents can be collected. Sublimation is an excellent technique to remove solvents from the polymer composition. The use of symmetric solvents increases the viability / feasibility of this method [85]. The polymer blending synthesizing steps via freeze-drying are shown in Fig. 5. According to Fig. 5, first, the polymers are dissolved in a suitable solvent, and then the solvent temperature is reduced by placing it in a cold chamber to form solvent crystals. It is then taken under severe temperature reduction to remove the solvent from the sample, and finally, a polymer aerosol is formed.

\subsubsection{Latex blending}

The latex polymer composition is another method of manufacturing and synthesizing polymer blends. Creating resistant polymer mixtures with stable dispersion (emulsion phase) of polymer particles on the microsurface in any specific aqueous medium is one of the advantages of this method. The main factor in making such blends is selecting auxiliary polymers in the form of latex or emulsion and the appropriate mixing process to create a homogeneous latex of small size and distribution of discrete phases [86, 87]. Several types of research have been reported in the synthesis of the polymeric blending with the methods mentioned are listed in Table 3 .

Table 3. Summary of several research works in the field of synthesis of polymeric blending.

\begin{tabular}{|c|c|c|c|}
\hline Polymer blend & System & Description & Ref. \\
\hline \multicolumn{4}{|c|}{ Mechanical (melting) blending } \\
\hline $\begin{array}{l}\text { High-density polyethylene } \\
\text { recycled } \\
\text { polytetrafluoroethylene } \\
\text { micronized powder } \\
\text { (HDPE/rPTFE) }\end{array}$ & $\begin{array}{l}\text { Investigation of mechanical, gel fraction, } \\
\text { morphological and thermal properties }\end{array}$ & $\begin{array}{l}\text { - Improves the thermal stability of the polymer composition by increasing rPTFE } \\
\text { - Increased tensile strength } \\
\text { - Improves adhesion between rPTFE micronized powder and HDPE matrix using } \\
\text { electron beam irradiation } \\
\text { - Increases storage module }\end{array}$ & [88] \\
\hline $\begin{array}{l}\text { Polypropylene }(\mathrm{PP}) \text { and } \\
\text { thermoplastic polyurethane } \\
\text { (TTPU) }\end{array}$ & $\begin{array}{l}\text { Evaluation of performance improvement } \\
\text { of polypropylene and thermoplastic } \\
\text { polyurethane using ompatibilizer- } \\
\text { polypropylene grafted maleic anhydride } \\
\text { (MA) to produce a stable and } \\
\text { environmentally friendly polymer blend }\end{array}$ & $\begin{array}{l}\text { - Increases thermal stability using a polymer combination of PP and TTPU } \\
\text { - Increases thermal stability by adding MA to PP and TTPU structures } \\
\text { - Improves interfacial compatibility and adhesion }\end{array}$ & [89] \\
\hline $\begin{array}{l}\text { Polypropylene (PP) and low- } \\
\text { density polyethylene (LDPE) }\end{array}$ & $\begin{array}{l}\text { Synthesis of the polymer composition of } \\
\text { polypropylene and low-density } \\
\text { polyethylene to prevent degradation } \\
\text { during the recycling process }\end{array}$ & $\begin{array}{l}\text { - Reduction of plastic waste and production of a valuable material using PP } \\
\text { polymer blend with low-density polyethylene mixture additive }\end{array}$ & [90] \\
\hline
\end{tabular}


Table 3. Continued.

\begin{tabular}{|c|c|c|c|}
\hline Polymer blend & System & Description & Ref. \\
\hline \multicolumn{4}{|l|}{ Solution blending } \\
\hline $\begin{array}{l}\text { Styrene-butadiene rubber (SSBR)/ } \\
\text { trans-1,4-polyisoprene (TPI) }\end{array}$ & $\begin{array}{lcr}\begin{array}{l}\text { Evaluation of } \\
\text { performance }\end{array} & \begin{array}{c}\text { the } \\
\text { of }\end{array} & \begin{array}{r}\text { structural } \\
\text { polymer }\end{array} \\
\text { composition } & & \end{array}$ & - Improves the performance of the polymer structure blending & [91] \\
\hline $\begin{array}{l}\text { Sulfonated polysulfone (SPSf) and } \\
\text { Tröger's base (TB) polymer }\end{array}$ & $\begin{array}{l}\text { Evaluation of mechanical strength } \\
\text { improvement and separation } \\
\text { performance of ultrafiltration } \\
\text { membranes }\end{array}$ & $\begin{array}{l}\text { - Increased surface area and total porosity } \\
\text { - Increasing the water contact angle by adding hydrophobic cell polymer and } \\
\text { forming the acid crosslinking structure } \\
\text { - Increased the mechanical strength of the membrane }\end{array}$ & [92] \\
\hline $\begin{array}{l}\text { Polyvinyl alcohol/ poly (N-vinyl } \\
\text { pyrrolidone) (PVA/PVP) }\end{array}$ & $\begin{array}{l}\text { Evaluation of dielectric } \\
\text { conductivity and conductivity in the } \\
\text { polymer blending }\end{array}$ & $\begin{array}{l}\text { - Increase in frequency-dependent dielectric constant }\left(\varepsilon^{\prime}\right) \text { with increasing } \\
\text { concentration of reduced graphene oxide }(\mathrm{rGO}) \\
\text { - Increased } \mathrm{AC} \text { conductivity by increasing } \mathrm{rGO} \text { doping concentration }\end{array}$ & [93] \\
\hline \multicolumn{4}{|l|}{ Freeze Drying } \\
\hline $\begin{array}{l}\text { Poly(L-lactic } \\
\text { (PLLA)/poly(methyl } \\
\text { methacrylate) (PMMA) }\end{array}$ & $\begin{array}{l}\text { Construction of a stable polymer } \\
\text { blending of poly (L-lactic acid)/ } \\
\text { poly (methyl methacrylate) using } \\
\text { selective hydrolysis degradation } \\
\text { without any organic solvents }\end{array}$ & $\begin{array}{l}\text { - Using dry ice to prevent the accumulation of monoliths } \\
\text { - Control of porosity and pore density by increasing the weight fraction of PLLA } \\
\text { - The adjustability of mesoporous by changing the mechanical composition of } \\
\text { mixed polymers by making integrated mesoporous polymer without organic } \\
\text { solvent }\end{array}$ & [94] \\
\hline $\begin{array}{l}\text { Carboxymethyl cellulose (CMC) } \\
\text { and alginate (ALG) }\end{array}$ & $\begin{array}{l}\text { Evaluation of a polymer } \\
\text { composition for the practical } \\
\text { fabrication of mucosal adhesive } \\
\text { wafer in effective sublingual } \\
\text { delivery and preservation of protein } \\
\text { vaccines }\end{array}$ & $\begin{array}{l}\text { - High adhesion to sublingual mucosal tissue, extensive leaching tolerance and } \\
\text { improved protein penetration into tissues using high CMC content wafers } \\
\text { - Improving mechanical strength, protection against a model enzyme ( } \beta \text { - } \\
\text { galactosidase) against lyophilization and heat challenge using wafers with high } \\
\text { ALG content }\end{array}$ & [95] \\
\hline $\begin{array}{l}\text { Poly(propylene glycol)-silane- } \\
\text { poly(ethylene glycol) (PPG-Si- } \\
\text { PEG) and Polyvinylidene Fluoride } \\
\text { (PVDF) }\end{array}$ & $\begin{array}{l}\text { Fabrication of gravity-driven } \\
\text { membranes with high flux and low } \\
\text { deposition (GDM) using } \\
\text { amphiphilic polymer composition } \\
\text { of poly (propylene glycol) -silane- } \\
\text { poly (ethylene glycol) (PPG-Si- } \\
\text { PEG) and synthesized in } \\
\text { polyvinylidene fluoride matrix }\end{array}$ & $\begin{array}{l}\text { - Improved hydrophilicity using PEG } \\
\text { - Increased water flux of membranes } \\
\text { - Improved antifouling properties of the modified membrane }\end{array}$ & [96] \\
\hline
\end{tabular}

\section{Latex blending}

Acrylic (BA-St-AA) copolymer
and Polydimethylsiloxane
(PDMS) homopolymer

Poly(methyl methacrylate)/
Polystyrene (PMMA/PS)

\begin{tabular}{ll}
\hline & Construction of polymer \\
Polyurethane/ polyacrylic esters & $\begin{array}{l}\text { omposition of polyurethane/ } \\
\text { polyacrylic esters using hybrid } \\
\text { polymer latex method }\end{array}$
\end{tabular}

Assembly of a stable polymer composition using resins used in coatings to increase soil shrinkage resistance using latex method
- Creating continuous and transparent films with low pollution pickup properties using $10-12 \%$ by weight PDMS in compounds

- Creating a suitable outer coating and uniformity of hydrophobic state of the composition by mixing acrylic and silicone latexes in a two-state particle size distribution

- Morphological instability of polymer composition

- Proper compatibility of polymer composite components

- Suitable stability Morphology of polymer composition

- Reactivity of NCO chain with water as an extender

- Improving their mechanical properties with the properties of the prominent [99] component films (latex polyurethane and acrylic)

\subsubsection{Polymer blending application}

The polymer blend is a practical way to save time and money to produce materials with desirable properties. The polymer blend plays an essential role in the fabrication of MMMs in the gas separation industry. Robson upper bond showed polymer membranes weakness using a diagram in 1991 and 2008, such as competitiveness, and two critical factors; permeability and selectivity [100]. Recent studies aimed at achieving commercialization of membranes indicate that the interaction between polymers and gases and the construction of a polymer blend with high selectivity and permeability are of particular importance. Miscible polymer blend plays an essential role in increasing the mixed matrix membranes performance due to creating a homogeneous selective layer. Table 4 reports several studies performed to improve a mixed matrix membranes performance using a polymer blend. 
Table 4. Several studies performed to improve a mixed matrix membranes performance using a polymer blend.

\begin{tabular}{|c|c|c|c|}
\hline System studied & Polymer blend & Research results & Ref. \\
\hline \multirow{6}{*}{$\mathrm{CO}_{2}$ gas separation } & $\begin{array}{l}\text { Polyethersulfone (PES)/ polyimide (PI) coated with } \\
\text { polydimethylsiloxane }\end{array}$ & $\begin{array}{l}\text { - Construction of a high-performance polymer blend for industrial gas } \\
\text { separation }\end{array}$ & [101] \\
\hline & $\begin{array}{l}\text { Polyvinyl pyrrolidone (PVP) and polyvinyl alcohol } \\
\text { (PVA) }\end{array}$ & $\begin{array}{l}\text { - Making low-cost and straightforward membranes with polymer } \\
\text { composition and improving the penetration of } \mathrm{CO}_{2} \text { in the membrane } \\
\text { shows excellent potential for membranes' industrial applications. }\end{array}$ & [102] \\
\hline & $\begin{array}{l}\text { Polymers of intrinsic microporosity (PIM-1) /6FDA- } \\
\text { DAM }\end{array}$ & $\begin{array}{l}\text { - Improving the performance of composite network membranes in } \mathrm{CO}_{2} \\
\text { gas separation using polymer blend polymers of intrinsic } \\
\text { microporosity (PIM-1)/ 6FDA-DAM } \\
\text { - Increasing the permeability by increasing the amount of PIM-1 in the } \\
\text { polymer structure and increasing the d-spacing of the polymer chains }\end{array}$ & [103] \\
\hline & $\begin{array}{l}\text { Polyvinyl alcohol (PVA)-modified polyether block } \\
\left.\text { amide) (pebax }{ }^{\circledR} 1657\right)\end{array}$ & $\begin{array}{l}\text { - Improves the absorption and permeability of carbon dioxide in the } \\
\text { membrane structure }\end{array}$ & [104] \\
\hline & Matrimid/ polyvinylidene fluoride (PVDF) & $\begin{array}{l}\text { - Improved gas permeability of membranes made using polymer } \\
\text { composition compared to neat membranes }\end{array}$ & [105] \\
\hline & $\begin{array}{l}\text { Polyvinylchloride-polyoxyethylene methacrylate } \\
\text { (PVC-POEM) }\end{array}$ & $\begin{array}{l}\text { - Development of high-performance membranes for gas separation } \\
\text { - Improve the morphological and transition properties of the membrane }\end{array}$ & {$[106]$} \\
\hline \multirow{4}{*}{ Nano filtration } & Polyethersulfone/ polyamide & $\begin{array}{l}\text { - Increased hydrophilicity of PES/ PI membranes with the modification } \\
\text { process } \\
\text { - Improved membrane performance in } \mathrm{NaCl} \text { separation }\end{array}$ & [107] \\
\hline & Polysulfone/ poly (1,4-phenylene ethersulfone) & $\begin{array}{l}\text { - Increase membrane mechanical strength and decrease membrane } \\
\text { deposition } \\
\text { - Improving membrane performance in the removal of } \mathrm{NaCl}, \mathrm{MgCl}_{2} \text {, } \\
\mathrm{MgSO}_{4}, \mathrm{~K}_{2} \mathrm{SO}_{4}, \mathrm{KCl}, \mathrm{CaCl}_{2}\end{array}$ & [108] \\
\hline & $\begin{array}{l}\text { P-amino benzoic acid/ polyisobutylene-altmaleic } \\
\text { anhydride/ polysulfone }\end{array}$ & $\begin{array}{l}\text { - Increased membrane surface hydrophilicity } \\
\text { - Improved nanofiltration membrane performance in } \mathrm{NaCl} \text { removal }\end{array}$ & [109] \\
\hline & $\begin{array}{l}\text { Poly-diallyl dimethylammonium chloride (PDDA)/ } \\
\text { hydrolyzed polyacrylonitrile }\end{array}$ & - Reduce clogging and improve membrane performance & {$[110]$} \\
\hline \multirow[t]{2}{*}{$\begin{array}{l}\text { Propylene/propane } \\
\text { separation }\end{array}$} & $\begin{array}{l}\text { Polysulfone (PSF)/ poly (polyethylene glycol) methyl } \\
\text { ether methacrylate (PEG) }\end{array}$ & $\begin{array}{l}\text { - Uniform increase of distance between polymer chains with increasing } \\
\text { PEG content } \\
\text { - Improved surface adhesion between ZIF-8 and the polymer by } \\
\text { increasing the PEG content } \\
\text { - Improve mechanical strength and increase the permeability }\end{array}$ & [111] \\
\hline & $\begin{array}{l}\text { 4,4'-(Hexafluoroisopropylidene) diphthalic anhydride, } \\
\text { (6FDA)/ DAM }\end{array}$ & - Improves membrane separation performance & [112] \\
\hline $\begin{array}{l}\text { Water } \\
\text { application }\end{array}$ & Polyethersulfone/sulfonated polysulfone (PES/SPSF) & $\begin{array}{l}\text { - Reduce clogging and membrane deposition } \\
\text { - Increase membrane separation performance }\end{array}$ & [113] \\
\hline \multirow[t]{2}{*}{ Gas mixture } & $\begin{array}{l}\text { Polydimethylsiloxane (PDMS), polyisoprene (PI) and } \\
\text { polyurethane (PU) }\end{array}$ & - Improves membrane performance in gas separation & [114] \\
\hline & polyurethane and polyvinyl acetate blend & - Increase permeability and selectivity by using a polymer blend & [115] \\
\hline $\begin{array}{l}\text { Removal of toluene } \\
\text { from water }\end{array}$ & PDMS/blended PES & $\begin{array}{l}\text { - Increase the enrichment factor by increasing the polymer } \\
\text { concentration in the top layer } \\
\text { - Improve evaporative performance in fabricated membranes }\end{array}$ & {$[116]$} \\
\hline $\begin{array}{l}\text { Removal of toluene } \\
\text { from methanol }\end{array}$ & Polyurethane-polydimethylsiloxane (PU-PDMS) blend & $\begin{array}{l}\text { - Methanol molecules release faster than toluene } \\
\text { - Enhance membrane performance using polymer blends }\end{array}$ & [117] \\
\hline Microfiltration & Cellulose acetate-polyurethane blend & - Improves permeability and membrane separation performance & [118] \\
\hline Humic acid removal & Polyethersulfone (PES)/ polyvinyl pyrrolidone (PVP) & $\begin{array}{l}\text { - Improved anti-fouling performance and optimal flux with the least } \\
\text { amount of fouling resistance } \\
\text { - Increase anti-rot ability }\end{array}$ & [119] \\
\hline
\end{tabular}




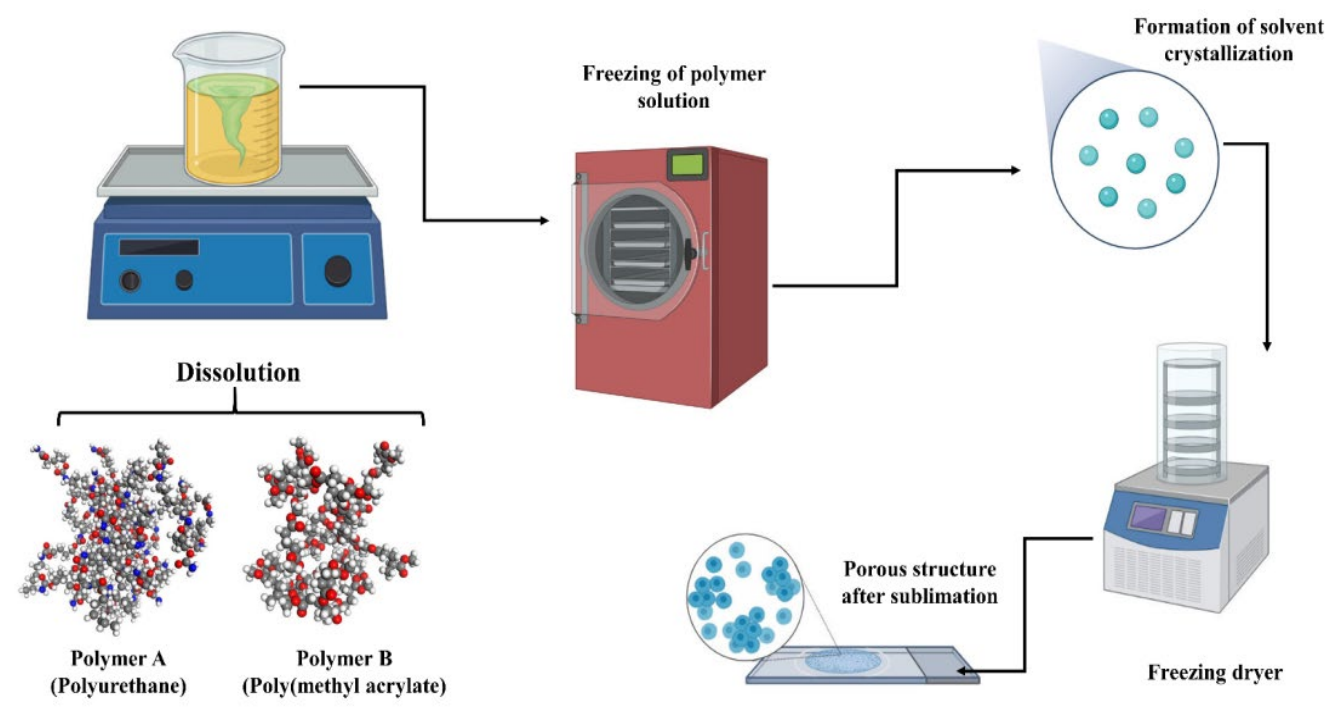

Fig. 5. A schematic of construction polymer blending using freeze-drying.

\subsection{Fillers}

The most important fillers applications are to prevent the accumulation of particles, void formation, blockage of pores and rigidification of the polymer in the development of MMM and improve the gas separation

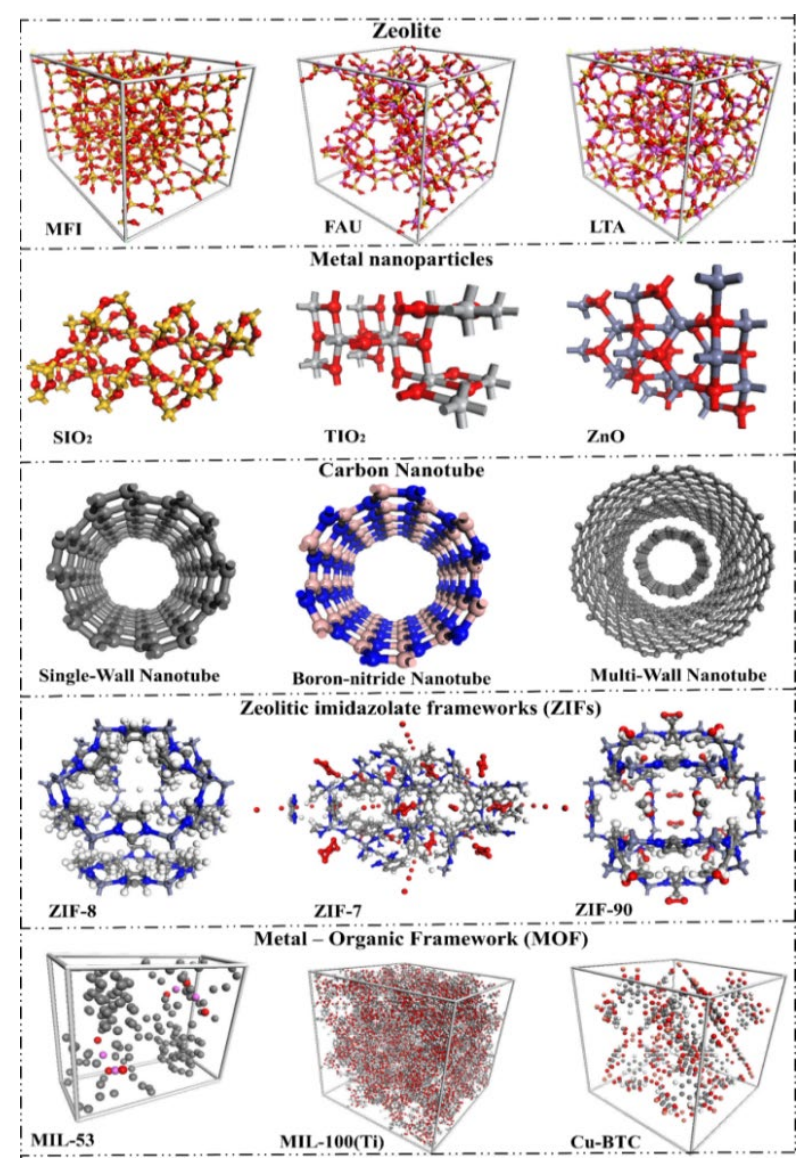

Fig. 6. Some popular fillers used in mixed matrix membranes construction. performance. On the other hand, it may have adverse effects and reduce membrane performance based on the fillers nature [120, 121]. Improving permeability performance in mixed matrix membranes due to the presence of fillers and effects such as through membranepenetrant interaction, molecular sieving, free volume, and polymer chain strength are other advantages of fillers [122]. In general, improving the performance of mixed matrix membranes in terms of physicochemical and transition properties of membrane structures is the main advantage of using fillers [27]. One of the main concerns in the mixed matrix membranes construction is the control of chemical structure, surface chemistry, and the type and amount of filler phase. In fact, the properties of both phases affect the morphology and membrane separation performance. It should be noted that, prevention of accumulation, proper distribution in the polymer matrix, and also low tendency of polymers to interact with fillers (especially glass polymers due to low mobility of polymer chains, compared to inorganic fillers) are among the complexities of mixed matrix membrane construction. Synthesis and surface modification methods are techniques to overcome the weaknesses of fillers to improve membranes' performance. Zeolites, graphene oxide (GO), metal nanoparticles, carbon nanotubes (CNTs), zeolite imidazole frameworks (ZIFs) and metal-organic frameworks (MOFs) are the most common fillers used in the mixed matrix membranes construction (Fig. 6). Common filler synthesis methods and their advantages and disadvantages are reported in Table 5.

\subsubsection{Zeolites}

Zeolites are a group of crystalline, porous, and hydrated aluminosilicates with exchangeable cations of alkaline and alkaline earth metals that are used as adsorbents in various industries [123]. Zeolites are known as suitable fillers for utilization in mixed matrix membranes due to channels and cavities of different sizes with unique physicochemical properties with high thermal and chemical stability [124]. Achieving a high-performance zeolite-filled mixed matrix membrane is entirely influenced by the proper choice of zeolite type. According to previous studies, zeolites used with a pore size of 4 to 10 $\AA$ have an excellent performance in improving the mixed matrix membrane properties [125]. 
Table 5. Standard filler synthesis methods and their advantages and disadvantages.

Method
Hydrothermal [151]
- Hydrothermal is a method based on crystals formation and growth due
to chemical reactions and changes in the solubility of materials in an
aqueous solution under appropriate temperature and pressure.
- In this method, the reactants are dissolved in the appropriate solvent
first. Ultrasonic waves are used if needed to dissolve or distribute the
pre-material better in the solution. Then the solution of raw materials is
poured into the Autoclave. The autoclave containing the reactive
solution is heated to the appropriate temperature. As a result of this
heating, the pressure inside the autoclave is increased, and suitable
conditions for the premedications reaction are provided. After enough
time to perform a chemical reaction inside the autoclave, the heating is
stopped; the products come out of it and heat if needed for drying and
calcination.
- The synthesis gel is heated in an autoclave at a specified temperature
(induction period)
- The reaction of the mineralizing agent (sodium hydroxide or fluoride
ion) with the chemicals in the synthesis gel (silicon and aluminum)
(nucleation)
(crystal growth)

Disadvantages
- Proper controllability of process parameters

- Ability to create crystalline phases that are not stable at the melting point.

- Grow materials that have high vapor pressure near their melting points
- High temperature $\sim 90{ }^{\circ} \mathrm{C}$ to $200{ }^{\circ} \mathrm{C}$

- Costly process

- Impossibility of observing crystals during growth

\section{Microwave [152]}

- The initial heating rate (reaching the desired temperature of the solution to start the reaction) is increased by using the microwave, and the synthesis process is accelerated. Therefore, by reducing chemical reactions from a few hours to a few minutes, energy efficiency will also increase. Factors affecting microwave-synthesized nanomaterials final properties include solvent type, reactive chemical composition, coating agents, temperature, pressure, and wave's frequency.
- Reduce synthesis time

- Significant enhancement of reaction rates

- High selectivity

- Improve penetration characteristics by - Heterogeneous reaction mixture controlling membrane morphology, orientation, composition

- Perform chemical reactions at very high temperatures

- "Hot spots" yielded result in a "super-heating" effect

- No direct contact between energy source and solution

- High efficiency, environmentally friendly and economical

- Increase the crystallization rate in a short time,

Sol-Gel [153]

- Production of amorphous gel from the interaction of aluminate and silicate or silica sol or metal alkoxides

- additional hydrothermal treatment to get crystalline phase

- nucleation and quick dissolution of the gel
- the restricted penetration depth of microwave irradiation into absorbing materials

- Microwave vial explosion due to increased pressure of heating reactions far away from the boiling point of the solvent

- The high cost of precursors such as metal alkoxides

- Time-consuming reaction steps, especially the action step

- Fractures on the surface of the layers created and fragmentation of the specimen
- Resulting in small particle size with the narrow particle size distribution

- No need for expensive equipment

- Manufacture of high purity products

- The high degree of homogeneity due to reaction in the liquid phase

- Ability to control the percentage of porosity (by changing the temperature and time)

\section{Sedimentation processes}

- In this method, the raw materials are first dissolved in a standard solvent, and then the precipitating agent is added. The precipitating agent can be a complex, reducing or oxidizing agent. The reaction was then stabilized after nanoparticles' formation by spatial, electrostatic, or

- The simplicity of the process

- No need for advanced equipment 
Table 5. Continued.

\begin{tabular}{|c|c|c|}
\hline Method & Advantages & Disadvantages \\
\hline $\begin{array}{l}\text { Chemical vapor deposition, CVD } \\
\text { - Reaction gases (precursors) enter the reaction chamber at a suitable } \\
\text { and controlled temperature } \\
\text { - Formation of a solid layer of silicon carbide ( } \mathrm{SiC}) \text { due to the collision } \\
\text { of these gases with the hot substrate } \\
\text { - Trapping of exhaust gas ( } \mathrm{HCl}) \text { by } \mathrm{NaOH} \text { and condensation by } \\
\text { nitrogen }\left(\mathrm{N}_{2}\right)\end{array}$ & $\begin{array}{l}\text { - Fabrication of various nanostructures } \\
\text { - Fabrication of various nanostructures due to } \\
\text { high reaction speed } \\
\text { - Use of various precursors due to the high } \\
\text { reaction temperature } \\
\text { - Lack of by-products } \\
\text { - Control the structure, shape and composition of } \\
\text { the desired products by changing the reaction } \\
\text { medium }\end{array}$ & $\begin{array}{l}\text { - High energy consumption } \\
\text { - high temperature } \\
\text { - Inadequate quality of produced films }\end{array}$ \\
\hline $\begin{array}{l}\text { Physical vapor deposition, PVD [154] } \\
\text { - Stages of nanomaterial formation } \\
\text { - Adsorption of atoms or molecules on the surface of the substrate } \\
\text { - Horizontal penetration of adsorbed material on the surface } \\
\text { - Forming bonds with each other as well as with substrate atoms } \\
\text { - Atomization and compaction of atoms } \\
\text { - Creating developed crystal structures and forming microstructures }\end{array}$ & $\begin{array}{l}\text { - Produce thin films with a thickness of less than } \\
100 \mathrm{~nm} \\
\text { - Process safety } \\
\text { - Use on any inorganic substance }\end{array}$ & $\begin{array}{l}\text { - Create a uniform film on a smooth } \\
\text { bed surface } \\
\text { - Formation of large nuclei in case of } \\
\text { improper bonding of film atoms with } \\
\text { substrate atoms and reduction of final } \\
\text { film density } \\
\text { - High production costs } \\
\text { - The process requires sophisticated } \\
\text { machines and skilled operators }\end{array}$ \\
\hline
\end{tabular}

Reverse micelle and microemulsion

- Coprecipitation: Coprecipitation is commonly used to manufacture metal sulfides, oxides, and carbonates of metals and silver halides. In this method, two inverse micelles containing cationic and anionic ions are mixed. Because each action takes place in a nanometer water pool, the products will be nanoscale.

- Resuscitation: By dissolving the metal salts in the reverse micelles, the salts in the water pool are separated into the micelles and then reduced. As a result, sediments form inside the water cavities and prevent them from clotting. This method uses strong reductants such as $\mathrm{N}_{2} \mathrm{H}_{4}, \mathrm{NaBH}_{4}$ and $\mathrm{H}_{2}$.

- Hydrolysis: The hydrolysis reaction is used to make metal oxide nanomaterials. In this method, metal alkoxides are dissolved in the oil phase and react with water in the micelles.

Electrochemical process

- Using this method, nanomaterials with zero-dimensional structure (nanoparticles), one-dimensional and two-dimensional, can be prepared. Two-dimensional nanomaterials are prepared by electrochemical deposition of materials on a suitable substrate. Different molds such as alumina or copolymer molds can also be used to prepare one-dimensional nanomaterials (nanowires and nanorods). These molds are also used to make nanoparticles, with the difference that the pores' length is very short.
- Construction of nanomaterials with efficiency

- Production of intelligent nanoparticles in the pharmaceutical industry

- Manufacture of single spray nanomaterials of different sizes

- Easy oxygen removal in oxygen-sensitive nanomaterials due to the use of organic matter

- High stability

- Nanomaterial surface modifiability
- System complexity

- Identify and select the appropriate surfactant

- Expensive surfactant
- Low cost

- Suitable temperature for testing

- Low energy consumption

- Use inexpensive solutions

- Low pollution and environmental friendliness

- Controllability of test conditions

- The density of composed nanomaterials
- The need to use the primary sublayer

- The need to remove the substrate (thinning) and thus increase the reaction steps

- Lack of access to spherical morphologies in cases where the substrate is used

- Toxicity of the electrolytes used

- Difficulty coordinating regenerative potential in the fabrication of alloys or binary metals

Thermal decomposition (thermolysis)

- Thermal degradation is a chemical reaction in which chemicals are converted to at least two other chemicals under the influence of heat. The precursor is converted to a stable compound under appropriate thermal conditions, and the waste material is evaporated removed.

- High purity of reaction products

- High controllability of the reaction process

- The wide variety of reaction precursors
- high temperature

- Wide particle size distribution

- Increase the adhesion of particles to each other

- Organic-metal compounds or metal complexes are used as a metal source in hot surfactant solution in this method. 
The most widely-used zeolites in the mixed matrix membranes construction are TS-1, ETS-10, SAPO-34, AIPO, MCM-41, COK-12, MFI, BEA, GIS, FAU, NaA, NaX, NaY, ZSM-5 and LTA [126]. The creation of "cage sieve" morphology and non-selective cavities due to inappropriate adhesion at the zeolite-polymer interface, production at high operating temperatures and costly process are disadvantages of using zeolites in the fabrication of mixed matrix membranes [127]. Surface modification using silanes, diluted solution coating of highly permeable silicone rubber on the membrane, coupling agent, the antiplasticization process of the polymer matrix, low molecular weight additive and long aliphatic, polyaromatic compounds containing polar atoms are common methods of overcoming zeolitic weaknesses and improving the performance of mixed matrix membranes [125]. In general, zeolite is synthesized at temperatures between 90 and $200{ }^{\circ} \mathrm{C}$ over several hours to several weeks. The use of primary amorphous cell is the most effective and widely used method among the various techniques of making zeolite nanocrystals. The use of clear primary solutions and colloidal suspensions is one of the most influential and greatly applied forms of synthesis of zeolite nanocrystals. These suspensions are stable colloids, and the distributed zeolites in them do not cause sedimentation for a long time. Colloidal crystals give the production structures a unique purity and improve their performance by increasing zeolites' contact surface. The formation of smaller zeolite crystals is an important feature of zeolite synthesis in the finite space method in the absence of organic conducting agents $[128,129]$

\subsubsection{Metal nanoparticles}

In recent decades, metal nanoparticles in the mixed matrix membranes construction have received much attention from researchers owing to their potential applications for the membrane-based separation process, preventing the formation of non-selective cavities in the nanoparticle/polymer matrix interface, improving the mechanical and physicochemical properties [125]. Factors such as chemical composition, size, shape, structure, and synthesis method determine metal nanoparticles' properties and applications. Physical and chemical processes are used as the primary method of synthesizing metal nanoparticles. Solid evaporation and its conversion to supersaturated vapor to form homogeneous germination of nanoparticles are the basis of physical methods in constructing nanoparticles [130]. In physical processes, the resulting crystals' size is controlled by temporarily deactivating the evaporation source or slowing it down by entering gas molecules into the particle-containing colloid. The growth of nanocrystals in this method is usually high-speed. Therefore, the synthesis of nanocrystals in this method requires precise control over process parameters. Inert gas condensation, arc discharge, ion sputtering, laser ablation and pyrolysis are standard physical methods of making metal nanoparticles. Chemical methods are of particular importance in synthesizing various metal nanoparticles and are usually performed under mild conditions. The basis of chemical techniques is the preparation of separate nanocrystals dispersed in a solvent (sol). It is possible to produce cells in both aquatic and organic environments [131, 132]. Some common chemical methods include reduction, solvothermal synthesis, photochemical synthesis, electrochemical synthesis, and thermolysis methods. Several factors that affect the construction of synthesized metal nanoparticles, such as impurities in the reaction medium (even in tiny amounts) will significantly affect the nanocrystal's final shape. For example, contaminants such as $\mathrm{Fe}^{+}, \mathrm{Fe}^{+2}$ and $\mathrm{Cl}^{-}$ions (in ppm) in the synthesis of silver nanocrystals change the morphology of the synthesized nanocrystals. Superior control over the chemical composition of the reaction system is necessary for the accurate synthesis of nanoparticles. Besides, trimmer clusters in an aqueous solution containing silver nitrate greatly affect the kinetics of the reduction process and the reaction path, resulting in nanoparticles' final deformities.

Moreover, gaseous species in the air, such as oxygen, nitrogen, carbon mono, and water vapor as by-products produced during the reaction, affect crystal plates' growth rate. For example, the morphology of platinum nanocrystals changes in the presence of oxygen gases and carbon monoxide. It should be noted that when the synthesis process is carried out in an aqueous medium, $\mathrm{H}^{+}$and $\mathrm{OH}^{+}$species are produced, the presence of which causes changes in the shape of various nanocrystals such as gold, silver, palladium and platinum [133, 134]. $\mathrm{SIO}_{2}, \mathrm{TIO}_{2}$ and $\mathrm{Al}_{2} \mathrm{O}_{3}$ have been known as nanoparticles in the construction of mixed matrix membranes.

\subsubsection{Carbon nanotubes (CNTs)}

Hollow cylinders made of graphite sheets are known as carbon nanotubes (CNT) which can have single-walled (SWNT) and multiwalled (MWNT) form. The unique physical and chemical properties of carbon nanotubes have led to significant research advances in recent years [135]. CNTs are an ideal material for reinforcing composites due to the presence of carbon-carbon bonds in graphite layers. Moreover, CNTs improve excellent magnetic, electrical and mechanical properties in membranes [136]. The use of carbon nanotubes as fillers in the construction of mixed matrix membranes improves the transitional (permeability and selectivity) and morphological (physicochemical) properties. CNT loading has a significant effect on the reinforcement and surface adhesion between nanotubes and polymers interfaces in mixed matrix membranes. Production of impurities during synthesis, lack of proper distribution in polymer matrices and organic solvents, and poor adhesion between CNTs and polymer matrix interface are some of the major problems of using nanotubes in mixed matrix membranes construction. Coating of the non-covalent surface with surfactants, attachment of polar groups to CNT sidewalls, surface functionalization, direct suspension of CNTs in polymer solution by ultrasound, surface oxidation and placement of hydrophilic functional groups on CNT surface have been commonly used to overcome the problems resulted from using nano-tubes in mixed matrix membranes construction. The tendency of CNTs to accumulate has made it challenging to distribute CNTs in the polymer matrix adequately due to the strong van der Waal attraction among the tubes [137]. Mechanical methods (ultrasonication, ball milling, extrusion, calendring, and highly-shearing/ highly-shorn mixing) and chemical processes (noncovalent and covalent methods) are common techniques for properly distributing nano-tubes in the polymer matrix [138, 139]. Chemical vapor deposition (CVD), arc discharge, laser ablation and high-pressure carbon monoxide are standard methods for constructing carbon nanotubes [140]. 


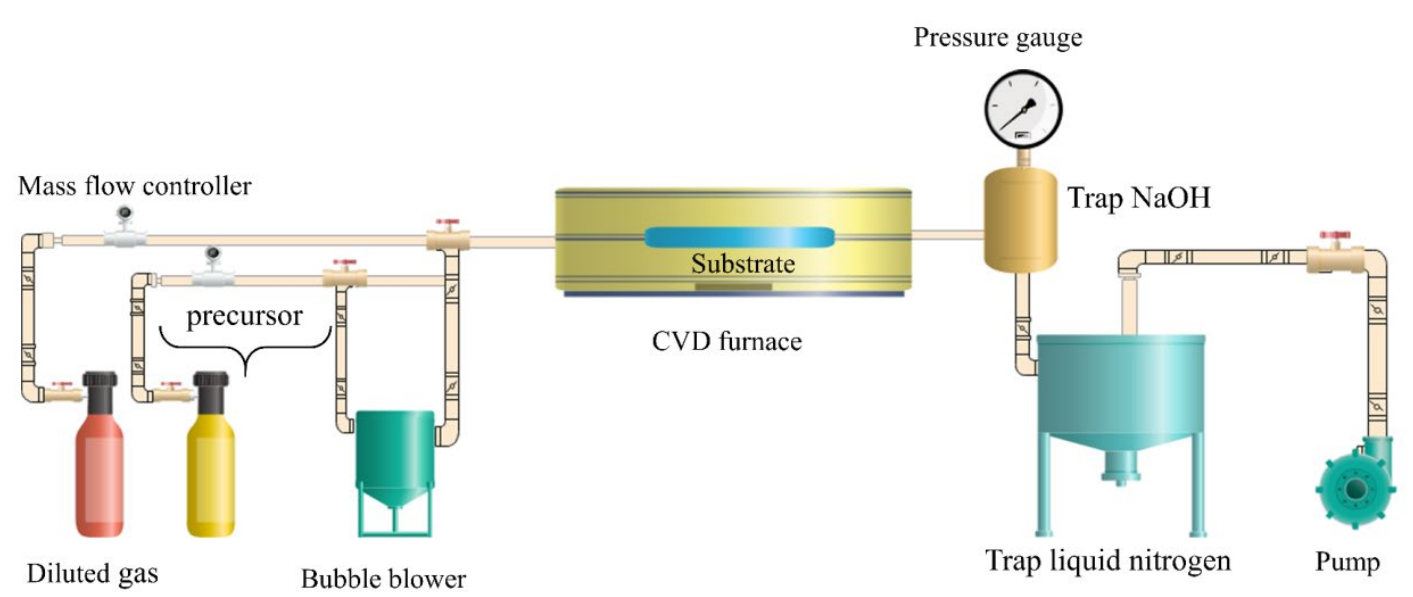

Fig. 7. Overview of the CVD process.

A chemical vapor deposition (CVD) method consists of a stream of gas or gases containing a chamber's precursor chemical compound. The chamber includes one or more hot surfaces. When chemical reactions occur near or on these hot surfaces, a deposit of the desired coating settles on them. Then, the layer is formed as a thin film on the hot surface. After the chemical reaction is completed, some by-product is formed next to the coating. These by-products are removed from the chamber and the raw gases that have not been consumed during the reaction remain. The CVD method is usually performed at temperatures above $1000^{\circ} \mathrm{C}$. Fig. 7 depicts an overview of the CVD process. As described in Fig. 7, the reacting gases (precursors) enter the reaction chamber at the appropriate and controlled temperature. A solid layer of silicon carbide $(\mathrm{SiC})$ is then formed by the reaction between the precursor and the hot substratum due to these gases' contact with the hot substratum. In the CVD method, a neutral gas such as argon (Ar) is usually used as the diluent. Sedimentation temperature and pressure are two limiting factors in this method. At the end of the process, the exhaust gas $(\mathrm{HCl})$ is trapped by $\mathrm{NaOH}$ and condensed by nitrogen gas $\left(\mathrm{N}_{2}\right)$ before leaving.

Uniformity of coatings; Possibility of depositing a wide range of materials; Very high purity of layers; No need for high vacuum and proper control of crystal structure, surface morphology and stoichiometry are the advantages of using the CVD method in making nano-tubes. Low safety, the toxicity of some of the compounds used, and the high cost of producing coatings with very high purity are some of this method's limitations.

\subsubsection{Graphene oxide (GO)}

Graphene is a two-dimensional (2D) sheet of carbon atoms in a hexagonal (honeycomb) configuration. The carbon atoms in graphene bond together with an SP2 hybrid. Graphene is the newest member of the multidimensional graphite carbon family of materials [141]. High yang modulus (about $1100 \mathrm{GPa}$ ), high resistance to breakdown (125 $\mathrm{GPa}$ ), suitable thermal conductivity (approximately $5000 \mathrm{~W} / \mathrm{mK}$ ), high electrical conductivity $\left(200,000 \mathrm{Vs} / \mathrm{cm}^{2}\right)$, high specific surface area $\left(2630 \mathrm{~m}^{2} / \mathrm{g}\right)$, and fantastic transition phenomena such as the Hall quantum effect are reported as prominent features of graphene [142]. In recent years, graphene oxide (GO) has been highly regarded by researchers in mixed matrix membranes production due to its outstanding properties such as high thermal and mechanical properties and high aspect ratio $(>1000)$ [143]. Graphene oxide has been widely used to improve mixed matrix membranes performance in oil-water separation, gas separation, water treatment, and energy storage. In recent years, extensive research has been conducted to develop different methods of producing graphene. Chemical exfoliation, chemical vapor deposition (CVD), chemical synthesis, mechanical cleaving (exfoliation) are used as graphene synthesis methods [144]. Synthesis, high-quality production and large scale pure graphene are significant challenges to constructing this material. Given scientists' attention to graphene and hope for its various applications in the near future, much research effort has been devoted to producing and understanding graphene's structure and properties [145].

Exfoliation of dispersed solution graphite by placing large alkaline ions between graphite layers is the basis of graphene oxide production method based on chemical exfoliation method. High quality and purity, low simplicity and complexity, suitable for laboratory research are the advantages of this method. However, limitations such as being unsuitable for industrial production, low performance and lack of access to high purity graphene synthesis have challenged this method [146].

\subsubsection{Metal-organic frameworks (MOFs)}

Metal-organic Frameworks (MOFs) is a new category of nanoporous materials widely used in the storage and separation of gases due to their large size cavities, high specific surface area, and small selectable absorption molecules and optical or magnetic responses in the presence of guest molecules. Metal-organic frameworks are formed by accumulating metal ions (intermediate group metals) and clusters as coordination centers and organic ligands (Halides: $\mathrm{Br}, \mathrm{Cl}, \mathrm{F}$ ) as binders [147]. The specific surface area is one of the most critical factors in assessing cavity capacity. In recent years, the available specific surface area has increased from $500 \mathrm{~m}^{2} / \mathrm{g}$, related to zeolites, to large amounts of $4500-5900 \mathrm{~m}^{2} / \mathrm{g}$ in MOFs. These values are much larger than the ideal values for carbon compounds $\left(2630, \mathrm{~m}^{2} / \mathrm{g}\right)$. In principle, the narrower the walls of the cavities the higher specific surface area. In mineral zeolites, the cavity walls are made of many $\mathrm{O}, \mathrm{Si}$ and $\mathrm{Al}$ atoms, 
while the MOFs have narrow walls. Synthesis of metal-organic frameworks is usually performed in the temperature range of $\sim 25-225$ ${ }^{\circ} \mathrm{C}$, pressures $\sim 0-20 \mathrm{~atm}$ and $\mathrm{pH} \sim 1-10$.

The cavities formed in this group of nanoporous materials have a specific size and shape distribution and are different from other porous materials. Therefore, it is possible to classify metal-organic frameworks according to the cavities' size [148]. In recent years, the use of metal-organic frameworks for gas storage and separation has expanded significantly. Nanoporous metal-organic frameworks have good electrical and catalytic properties and can be used as biological carriers in drug delivery applications. In general, metal-organic frameworks have specific physical and chemical properties and are structurally controllable. The final structure and properties of metalorganic frameworks are highly dependent on both the raw material parameters and the synthesis process. The raw materials influencing these frameworks' properties are ions or metal clusters and organic binders (also called secondary building blocks). Different physical, chemical properties and cavity sizes can be achieved by changing the ligands or the central metal. The design capability of these structures has turned them into targeted compounds. The synthesis of these materials for specific purposes is one of the plans that has made a considerable investment. MMMs-based MOFs have unique performance due to their high adsorption capacity and high chemical and thermal properties. Increasing the wetting properties between the two phases with strong interaction with the polymer matrix is one of the basic features of the organic part of MOFs. Zirconium, zinc, aluminum, and copper-based MOFs are widely used as filler in MMMs for $\mathrm{CO}_{2}$ separation from the gas mixture and discuss MOF fillers' influence in gas transport. Solvothermal, ball milling, microwave and ultrasonic are common methods of synthesizing metal-organic frameworks.

\subsubsection{Zeolite imidazole frameworks (ZIFs)}

Zeolite imidazole frameworks (ZIFs) are new class of porous materials that are a subset of MOFs. These materials have a topology similar to zeolites and have a set of characteristics of both zeolite and MOF groups, including diversity in the network and cavities structure, modifiable structure, high specific surface area, high thermal and chemical stability, etc. [149]. Therefore, various applications such as gas storage and separation, catalysts, chemical sensors, and nanotechnology equipment applications can be used. Usually, the cations of divalent metals such as $\mathrm{Zn}$ and $\mathrm{Co}$ and the nitrogen atoms of the imidazole anions of the linkers form ZIFs. Metal bonding imidazole metal is made with a bonding angle of $145^{\circ}$. These imidazole binders in ZIFs increase their hydrophobicity and provide better surface properties between the filler and the polymer matrix [150-154]. In general, ZIFs are suitable filler in MMMs for gas separation due to their large cavities with narrow pores. Common fillers used in the synthesis of mixed matrix membranes are listed in Table 6 .

Table 6. Common fillers used in the synthesis of mixed matrix membranes.

\begin{tabular}{|c|c|c|c|}
\hline Filler type & System studied & Outcome resulted & Ref. \\
\hline \multicolumn{4}{|l|}{ Zeolite } \\
\hline \multirow{4}{*}{ ZSM-5 } & Gas separation & $\begin{array}{l}\text { - Used in the fabrication of composite lattice membranes with matrimid }{ }^{\circledR} \text { polymer } \\
\text { - Increase } \mathrm{H}_{2} / \mathrm{N}_{2} \text { selectivity } \\
\text { - Establish a good bond between nanoparticles and polymers }\end{array}$ & {$[155]$} \\
\hline & $\begin{array}{l}\text { Ethanol/water separation: } \\
\text { preparation }\end{array}$ & $\begin{array}{l}\text { - Fabrication of composite network membrane with PDMS polymer } \\
\text { - Effective etching process to remove organic impurities in zeolite } \\
\text { - Increased hydrophobicity and roughness of ZSM-5 surface } \\
\text { - Increase tensile strength and swelling resistance by increasing the concentration of HF solution } \\
\text { - Increase the amount of absorption } \\
\text { - Increased surface adhesion of zeolite-PDMS }\end{array}$ & {$[156]$} \\
\hline & \multirow[t]{2}{*}{ Pervaporation process } & $\begin{array}{l}\text { - Fabrication of polyether block amide (PEBA) three component mixture matrix membranes with a } \\
\text { combination of ZSM-5 zeolite nanoparticles and ionic liquid [Hmim] [PF6] } \\
\text { - Use of ZSM-5 nanoparticles to improve membrane performance } \\
\text { - Significant improvement of membrane separation performance with simultaneous loading of ZSM-5 } \\
\text { and [Hmim] [PF6] in PEBA matrix }\end{array}$ & {$[157]$} \\
\hline & & $\begin{array}{l}\text { - Fabrication of ZSM-5/ polyether block amide (PEBA)/ polyester sulfone (PES) bilayer mixed matrix } \\
\text { membranes (MMMs) for separation of diffusion (PV) of ethyl acetate (EAc) from aqueous solutions } \\
\text { - Synthesis of ZSM-5 zeolite nanoparticles by hydrothermal method } \\
\text { - Increase diffusion flux and improve separation performance }\end{array}$ & {$[158]$} \\
\hline \multirow[t]{2}{*}{ Zeolite $13 \mathrm{X}$} & Gas separation & $\begin{array}{l}\text { - Investigation of gas separation properties of polyether block amide (PEBA) composite mesh membrane } \\
\text { combined with } 13 \mathrm{X} \text { nanoporous zeolite on a polysulfone (PSF)/ PE layer using the molecular dynamics } \\
\text { method } \\
\text { - Improved membrane separation performance with } 13 \mathrm{X} \text { zeolite loading }\end{array}$ & [159] \\
\hline & $\begin{array}{l}\text { Pos-combustion carbon } \\
\text { capture }\end{array}$ & $\begin{array}{l}\text { - Fabrication of } 13 \mathrm{X} / \mathrm{PEBAX} \text { composite network membranes for carbon dioxide separation } \\
\text { - Improved gas penetration properties at Zeolite } 13 \mathrm{X} \text { to } 15 \mathrm{~W} \% \text { filler load in PEBAX }\end{array}$ & {$[160]$} \\
\hline
\end{tabular}


Table 6. Continued.

\begin{tabular}{|c|c|c|c|}
\hline Filler type & System studied & Outcome resulted & Ref. \\
\hline Zeolite 4A & Gas separation & $\begin{array}{l}\text { - Preparation of mixed matrix membranes from PVAc as a polymer and zeolite } 4 \mathrm{~A} \text { as filler via soluble casting } \\
\text { method using dichloromethane solvent } \\
\text { - Better adhesion of MMMs prepared from calcined zeolite } 4 \mathrm{~A} \text {, compared to } 4 \mathrm{~A} \text { zeolite particles to PVAc } \\
\text { - Improving the stability of MMMs formulated from calcined zeolite } 4 \mathrm{~A} \\
\text { - Improving the performance of } \mathrm{CO}_{2}, \mathrm{O}_{2}, \mathrm{~N}_{2} \text { and } \mathrm{H}_{2} \text { diffusion properties }\end{array}$ & {$[161]$} \\
\hline Zeolite 4A & $\begin{array}{l}\text { Pervaporation } \\
\text { separation of water } \\
\text { isopropanol mixtures }\end{array}$ & $\begin{array}{l}\text { - Preparation of mixed matrix membranes using } 4 \mathrm{~A} \text { zeolite compound in matrimid } 5218 \text { polyamide using the } \\
\text { solution casting method } \\
\text { - Improved adhesion between zeolite and polymer phases at annealing temperature above } 250{ }^{\circ} \mathrm{C} \\
\text { - Increase the diffusion flux by increasing the zeolite content in the membranes }\end{array}$ & {$[162]$} \\
\hline \multirow[b]{2}{*}{ Zeolite $\mathrm{NaX}$} & \multirow[b]{2}{*}{ Gas separation } & $\begin{array}{l}\text { - Synthesis of matrix membranes of polymer/liquid/ solid three phase mixtures (PEBA/PEG/X nanoslit) } \\
\text { - Increasing the permeability coefficient and selectivity of } \mathrm{CO}_{2} \text { in membranes by increasing the pressure and } \\
\text { PEG loading }\end{array}$ & {$[163]$} \\
\hline & & $\begin{array}{l}\text { - Synthesis of mixed matrix membranes (MMM) by combining NaX nano-zeolite to polyether-block-amide } \\
\text { (pebax-1657) as an active layer on polyethersulfone pol membrane (PES) as a backing layer } \\
\text { - Synthesis of MMMs using a hydrothermal method using microwave heating } \\
\text { - Reduce the permeability coefficient for all tested gases } \\
\text { - Increase the ideal choice for } \mathrm{CO}_{2} / \mathrm{N}_{2} \text { and } \mathrm{O}_{2} / \mathrm{N}_{2}\end{array}$ & {$[164]$} \\
\hline \multirow{2}{*}{ MFI-type zeolite } & Gas separation & $\begin{array}{l}\text { - Investigation of structural properties-transport of matrix membranes of polyamide block amide (PEBA)- zeolite } \\
\text { (MFI) MMMs by molecular simulation (MS) and Monte Carlo technique (MC) } \\
\text { - Increase the penetration coefficient of } \mathrm{CO}_{2}, \mathrm{CH}_{4} \text { and } \mathrm{N}_{2} \text { by increasing the MFI load from } 10 \text { to } 20 \% \text { by weight } \\
\text { - Improving the performance of morphological properties of membranes }\end{array}$ & {$[165]$} \\
\hline & $\begin{array}{l}\text { Remove organic } \\
\text { structure-directing } \\
\text { agents (OSDA) }\end{array}$ & $\begin{array}{l}\text { - Synthesis of multilayer MFI zeolite composite membrane for removal of organic structure-guiding agents } \\
\text { - Synthesis by soluble casting using MFI zeolite nanoparticles with open pores as filler and PDMS as the } \\
\text { continuous phase } \\
\text { - Improves membrane separation performance }\end{array}$ & {$[166]$} \\
\hline \multirow[t]{2}{*}{ SAPO-34 } & $\mathrm{CO}_{2}$ removal & $\begin{array}{l}\text { - Solve the problem of poor compatibility between polymer matrix and inorganic filler in mixed matrix } \\
\text { membrane }(\mathrm{MMM}) \text { using (SAPO)-34 } \\
\left.\text { - Increased } \mathrm{CO}_{2} / \mathrm{N}_{2} \text { selectivity after treatment with 1-butyl-3-methylimidazolium ([Bmim] }[\mathrm{BF} 4]\right) \text { ion solution in } \\
\text { methanol }\end{array}$ & {$[167]$} \\
\hline & $\begin{array}{l}\mathrm{CO}_{2} / \mathrm{CH}_{4} \text { and } \mathrm{CO}_{2} / \mathrm{N}_{2} \\
\text { separation }\end{array}$ & $\begin{array}{l}\text { - Decrease the permeability coefficient and increase the selectivity } \\
\text { - Best performance of composite mesh membrane separation containing } 20 \% \text { by weight of SAPO- } 34\end{array}$ & {$[168]$} \\
\hline
\end{tabular}

\section{Metal nanoparticles}

- Synthesis of MMMs for $\mathrm{CO}_{2}$ separation using polyethylene glycol (PEG) based polyethylene glycol (UTFCMMM) containing functional $\mathrm{SiO}_{2}$ nanoparticles (SFSNPs)

- Enhance the improvement of $\mathrm{CO}_{2}$ separation performance using $\mathrm{SiO}_{2}$ particles in polymer matrices

$\mathrm{CO}_{2}$ separation - Synthesis of polyether-block-amide/ silica (PEBA/SiO2) MMMs for carbon dioxide separation

- Modification of nanoparticle surface with cis-9-octadecenoic acid for proper distribution in the polymer structure

- Improve the performance of separation properties

- Synthesis of composite mesh membrane of polyurethane mixture filled with different silica nanoparticles to evaluate the transport performance of carbon dioxide $\left(\mathrm{CO}_{2}\right)$ and methane $\left(\mathrm{CH}_{4}\right)$

$\mathrm{SiO}_{2} \quad$ Gas separation

- Improving the proper distribution of silica nanoparticles in MMMs by modifying the filler surface of silica with long hydrophobic chains

- Degradation of polymer chains and improvement of carbon dioxide penetration due to the increase in free volume

- Improve separation performance by modifying the surface of silica nanoparticles

- Synthesis of polysulfone composite mesh membrane filled with silica for separation oil/water separation

- Improving separation performance by adding graphene oxide and nanosilica particles to the polymer structure

- Increase the contact angle by adding silica nanoparticles to the structure

- Increase the yang modulus of the membrane by increasing the silica nanoparticles to the structure

Oil/water separation

- Improving the performance of polyester sulfone (PES) membranes using graphene oxide (GO) and silica $\left(\mathrm{SiO}_{2}\right)$ nanoparticle fillers in the treatment of oily wastewater

- Increases membrane performance in removing oil from water 
Table 6. Continued.

\begin{tabular}{|c|c|c|c|}
\hline Filler type & System studied & Outcome resulted & Ref. \\
\hline \multirow{3}{*}{$\mathrm{TiO}_{2}$} & Desalination processes & $\begin{array}{l}\text { - Synthesis of polyacrylonitrile (PAN) - } \mathrm{TiO}_{2} \mathrm{MMMs} \text { using solvent-induced phase separation (NIPS) in } \\
\text { desalination process } \\
\text { - Improvement of membrane thermal properties and proper interaction of } \mathrm{TiO}_{2} \text { nanoparticles with } \\
\text { polymer matrix }\end{array}$ & {$[174]$} \\
\hline & $\begin{array}{l}\mathrm{CO}_{2} / \mathrm{N}_{2} \\
\text { performance }\end{array}$ & $\begin{array}{l}\text { - Preparation of mixed matrix membranes (MMMs) using synthesized titanium dioxide }\left(\mathrm{TiO}_{2}\right) \\
\text { nanoparticles in polyether block amide matrix (PEBA) for } \mathrm{CO}_{2} / \mathrm{N}_{2} \text { separation } \\
\text { - Improve } \mathrm{CO}_{2} \text { penetration performance by adding } \mathrm{TiO}_{2} \text { to the polymer structure } \\
\text { - Modification of } \mathrm{TiO}_{2} \text { with dopamine (DA) and polyethyleneimine (PEI) } \\
\text { - Improved performance of synthesized membranes compared to upper bond Robeson } 2008 \text { using } \\
\text { modifying } \mathrm{TiO}_{2} \text { levels with dopamine (DA) and polyethyleneimine (PEI) }\end{array}$ & {$[175]$} \\
\hline & Humic acid adsorption & $\begin{array}{l}\text { - Synthesis of PVDF- } \mathrm{TiO}_{2} \text { (MMMs) to investigate membrane adsorption behavior for humic acid (HA) } \\
\text { removal } \\
\text { - Improves HA absorption at low pH }\end{array}$ & {$[176]$} \\
\hline $\mathrm{Al}_{2} \mathrm{O}_{3}$ & $\mathrm{CO}_{2} / \mathrm{CH}_{4}$ separation & $\begin{array}{l}\text { - MMMs preparation of polyether block amide/ } \mathrm{Al}_{2} \mathrm{O}_{3} \text { to investigate the transfer properties of } \mathrm{CO}_{2} \text { and } \\
\mathrm{CH}_{4} \\
\text { - Improved performance of separation properties of MMMs compared to neat membranes }\end{array}$ & {$[177]$} \\
\hline \multicolumn{4}{|c|}{ Carbon nanotubes (CNTs) } \\
\hline \multirow{2}{*}{$\begin{array}{l}\text { Carbon } \\
\text { (CNTs) }\end{array}$} & Nanofiltration application & $\begin{array}{l}\text { - Application of the phase inversion method in mixed matrix membranes based on } \\
\text { polyethersulfone/carbon nanotubes (PES/CNT) in the application of nanofiltration (NF) } \\
\text { - Improve MMM performance using CNT in NF process }\end{array}$ & [178] \\
\hline & $\begin{array}{l}\text { Pervaporation separation of } \\
\text { water-isopropanol mixtures }\end{array}$ & $\begin{array}{l}\text { - Synthesis of polyvinyl alcohol (PVA)/ modified carbon nanotubes MMMs to study pervaporation } \\
\text { separation of water-isopropanol mixtures } \\
\text { - Improving the performance of MMMs filled with poly styrene sulfonate modified carbon nanotubes } \\
\text { - Good compatibility and interactions between fillers and polymer matrix }\end{array}$ & [179] \\
\hline \multirow[b]{2}{*}{$\begin{array}{l}\text { Single-walled } \\
\text { carbon nanotube } \\
(\mathrm{SWNT})\end{array}$} & & $\begin{array}{l}\text { - Synthesis of an efficient polyethersulfone membrane filled with modified particles of single carbon } \\
\text { wall carbon nanotubes (DexDTM-g-SCNT) for the preparation of ultrafiltration membranes } \\
\text { - Improve the hydrophilic properties of membranes } \\
\text { - Excellent membrane performance improvement in water treatment and other separation fields }\end{array}$ & {$[180]$} \\
\hline & Water purification & $\begin{array}{l}\text { - Synthesis of a thin film (TFN) polyvinyl alcohol (PVA) nanocomposite membrane filled with single- } \\
\text { walled aluminosilicate (SWNT) nanotubes for the nanofiltration process } \\
\text { - Increase the hydrophilicity of the membrane surface by reducing the membrane roughness and reducing } \\
\text { the contact angles } \\
\text { - Increase the hydrophilicity of the membrane surface by decreasing the membrane roughness and } \\
\text { reducing the contact angles } \\
\text { - Increasing the diffusion flux using single-walled aluminosilicate nanotubes in the polymer matrix }\end{array}$ & [181] \\
\hline \multirow{2}{*}{$\begin{array}{l}\text { Multi-walled carbon } \\
\text { nanotubes } \\
\text { (MWNTs) }\end{array}$} & Water treatment & $\begin{array}{l}\text { - Synthesis of polysulfone hollow fiber membranes (PSUs) filled with oxidized multi-wall carbon } \\
\text { nanotubes (MWNTs) using polyvinyl pyrrolidone (PVP) solvent } \\
\text { - Increase the net water flux by adding nanotubes to the polymer structure } \\
\text { - Improve sediment resistance } \\
\text { - Increase membrane hydrophilicity by decreasing contact angle }\end{array}$ & {$[182]$} \\
\hline & $\mathrm{CO}_{2}$ separation & $\begin{array}{l}\text { - Membrane synthesis of new PFs based on fluorine biphenyl (cardo-PIM-1) filled with functionalized } \\
\text { multi-walled carbon nanotubes (f-MWCNTs) } \\
\text { - Increased absorption of } \mathrm{CO}_{2} \text { compared to } \mathrm{N}_{2} \\
\text { - Increase the performance of } \mathrm{CO}_{2} \text { separation performance }\end{array}$ & {$[183]$} \\
\hline $\begin{array}{l}\text { Boron nitride } \\
\text { nanosheets }\end{array}$ & Humic acid removal & $\begin{array}{l}\text { - Preparation of polysulfone based mixed matrix membranes with ultrafiltration (MMM) with two- } \\
\text { dimensional boron nitride sheet (BNNS) } \\
\text { - Increase water permeability and remove humic acid }\end{array}$ & [184] \\
\hline $\begin{array}{l}\text { Graphene } \\
(\mathrm{GO})\end{array}$ & Water treatment & $\begin{array}{l}\text { - Fabrication of graphene oxide-polysulfone (GO-PSF) mixture matrix membranes using a wet phase } \\
\text { inversion method } \\
\text { - Increased diffusion flux with increasing GO in the polymer matrix } \\
\text { - Increased diffusion flux with increasing GO in the polymer matrix } \\
\text { - Improves membrane performance in salinity removal }\end{array}$ & {$[185]$} \\
\hline
\end{tabular}


Table 6. Continued.

\begin{tabular}{|c|c|c|c|}
\hline Filler type & System studied & Outcome resulted & Ref. \\
\hline \multirow[t]{2}{*}{$\begin{array}{l}\text { Graphene } \\
\text { (GO) }\end{array}$} & $\begin{array}{l}\text { Removal of heavy metal from } \\
\text { aqueous }\end{array}$ & $\begin{array}{l}\text { - Synthesis of polyvinyl chloride (PVC) nanocomposite membranes of graphene oxide (GO) } \\
\text { nanofilms } \\
\text { - Improves membrane flux performance, chromium removal and deposition resistance } \\
\text { - Improves the performance of tensile strength and elongation of membranes }\end{array}$ & [186] \\
\hline & $\mathrm{CO}_{2} / \mathrm{CH}_{4}$ gas separation & $\begin{array}{l}\text { - Synthesis of polysulfone (PSF) hollow fiber mixture (HFMMMs) matrix membranes filled with GO } \\
\text { nanofibers } \\
\text { - Improved } \mathrm{CO}_{2} / \mathrm{CH}_{4} \text { gas separation performance }\end{array}$ & {$[187]$} \\
\hline \multicolumn{4}{|c|}{ Metal-organic frameworks (MOFs) } \\
\hline \multirow[b]{2}{*}{ UiO-66 } & Hydrogen purification & $\begin{array}{l}\text { - Preparation of mixed membrane-matrix (MMM) based on polyethylene matrix (PEI) with UiO-66- } \\
\mathrm{NH} 2 \text { organic framework filler (MOF) } \\
\text { - Improved membrane separation performance using UiO-66- } \mathrm{NH}_{2} \text { - particles in membrane structure }\end{array}$ & [188] \\
\hline & $\begin{array}{l}\text { dehydration of } \mathrm{C} 1-\mathrm{C} 3 \text { alcohols } \\
\text { via pervaporation }\end{array}$ & $\begin{array}{l}\text { - Mixed matrix membranes (MMMs) synthesis consisting of porous nanoparticles UiO-66- } \mathrm{NH}_{2} \text { and } \\
\text { 6FDA-HAB / DABA } \\
\text { - Improving the superior separation performance of UMO-66- } \mathrm{NH}_{2} \text {-based MMMs due to the presence } \\
\text { of hydrophilic groups (amino groups) }\end{array}$ & [189] \\
\hline \multirow{2}{*}{ MIL-53 } & $\mathrm{CO}_{2} / \mathrm{CH}_{4}$ gas separation & $\begin{array}{l}\text { - Construction of cellulose acetate membrane filled with } \mathrm{NH}_{2} \text {-MIL } 53 \text { (Al) particles to separate } \mathrm{CO}_{2} \\
\text { from } \mathrm{CH}_{4} \\
\text { - Decrease in } \mathrm{CO}_{2} / \mathrm{CH}_{4} \text { separation factor by increasing the temperature from } 30 \text { to } 50{ }^{\circ} \mathrm{C} \\
\text { - Increase of } \mathrm{CO}_{2} / \mathrm{CH}_{4} \text { separation factor by increasing the pressure from } 3 \text { to } 15 \text { bar }\end{array}$ & {$[190]$} \\
\hline & $\begin{array}{l}\text { Sulfonylurea herbicides in } \\
\text { aqueous environments }\end{array}$ & $\begin{array}{l}\text { - Synthesis of new mixed matrix membranes (MMM) from metal-organic framework (MOF) (MIL- } \\
53 \text { ) and poly vinylidene fluoride (PVDF) frameworks } \\
\text { - It was improved the performance of hybrid network membranes and a promising prospect for } \\
\text { sulfonylurea enrichment of aquatic environments. }\end{array}$ & [191] \\
\hline MIL-68 & $\mathrm{CO}_{2} / \mathrm{CH}_{4}$ separation & $\begin{array}{l}\text { - Synthesis of matrimid-based MMM filled with MIL-68 (Al) for } \mathrm{CO}_{2} / \mathrm{CH}_{4} \text { mixture separation } \\
\text { - Increased } \mathrm{CO}_{2} \text { permeability and } \mathrm{CO}_{2} / \mathrm{CH}_{4} \text { greening } \\
\text { - High impact on MIL-68(Al)/Matrimid MMM separation performance }\end{array}$ & [192] \\
\hline MIL-101(Cr) & Gas separation & $\begin{array}{l}\text { - Synthesis of mixed matrix membranes (MMMs) from intrinsic microporosity PIM-1 polymer filled } \\
\text { with MIL-101 to investigate the separation properties of } \mathrm{He}, \mathrm{H}_{2}, \mathrm{O}_{2}, \mathrm{~N}_{2}, \mathrm{CH}_{4} \text { and } \mathrm{CO}_{2} \\
\text { - Increase gases permeability by adding MIL-101 } \\
\text { - High } \mathrm{CO}_{2} \text { uptake and penetration }\end{array}$ & [193] \\
\hline MIL-125(Ti) & $\mathrm{CO}_{2}$ separation from $\mathrm{CH}_{4}$ and $\mathrm{N}_{2}$ & $\begin{array}{l}\text { - Preparation of mixed matrix membranes (MMMs) by adding MIL-125 (Ti) to matrimid } \mathbb{R} \text { polyimide } \\
\text { polymer matrix } \\
\text { - Improves good adhesion and dispersion of fillers in the polymer matrix } \\
\text { - Significant improvement in } \mathrm{CO}_{2} \text { penetration and adsorption } \\
\end{array}$ & [194] \\
\hline \multicolumn{4}{|c|}{ Zeolite imidazole frameworks (ZIFs) } \\
\hline ZIF-7 & $\mathrm{CO}_{2} / \mathrm{N}_{2}$ separation & $\begin{array}{l}\text { - Fabrication of pebax }{ }^{\circledR} 2533 \text { membrane filled with } \mathrm{ZIF}-7 \text { particles to separate } \mathrm{CO}_{2} \text { from flue gas } \\
\left(\mathrm{N}_{2}\right) \\
\text { - Functionalization of } \mathrm{ZIF}-7 \text { with three } \mathrm{NH}_{2}-, \mathrm{OH}-\text { and } \mathrm{CH}_{3} \mathrm{OH}-\text { binders } \\
\text { - Improved } \mathrm{CO}_{2} / \mathrm{N}_{2} \text { separation performance using functionalized } \mathrm{ZIF}-7 \text { particles }\end{array}$ & [195] \\
\hline ZIF-8 & Gas separation & $\begin{array}{l}\text { - Synthesis of MMMs MWCNTs - ZIF- } 8 \text { membranes embedded in pebax polymer matrix } \\
\text { - Increase the improvement of } \mathrm{CO}_{2} \text { permeability and increase the free volume of membranes by } \\
\text { adding ZIF- } 8 \text { particles } \\
\text { - Adding MWCNT inside ZIF-8 particles increases } \mathrm{CO}_{2} \text { uptake and improves } \mathrm{CO}_{2} / \mathrm{N}_{2} \text { selectivity }\end{array}$ & [196] \\
\hline ZIF-11 & Gas separation & $\begin{array}{l}\text { - Development of Pebax }{ }^{\circledR} 2533 \text { mixed matrix membranes filled with ZIF-11 crystals } \\
\text { - Excellent adhesion between ZIF-11 and polymer matrix } \\
\text { - Improve carbon dioxide permeability by adding ZIF-11 to pebax }{ }^{\circledR} 2533 \text { polymer }\end{array}$ & [197] \\
\hline ZIF-67 & Propylene/propane selectivity & $\begin{array}{l}\text { - Construction of 6FDA-DAM MMMs membrane filled with ZIF- } 67 \text { particles to form } \mathrm{C}_{3} \mathrm{H}_{6} / \mathrm{C}_{3} \mathrm{H}_{8} \\
\text { - Increased } \mathrm{C}_{3} \mathrm{H}_{6} \text { permeability improvement } \\
\text { - Very high resistance of MMM against plasticization }\end{array}$ & [198] \\
\hline ZIF-90 & Gas separation & $\begin{array}{l}\text { - Construction of mixed matrix membranes (MMMs) based on polyamide and (ZIF-90) } \\
\text { - Proper distribution of particles within the polymer matrix } \\
\text { - Improved permeability and gas absorption by MMMs }\end{array}$ & [199] \\
\hline
\end{tabular}




\subsection{Mixed matrix membranes synthesis method}

\subsubsection{Solution mixing}

Solution mixing is one of the simplest methods for preparing mixed bed membranes. In this method, the polymer is dissolved in a suitable solvent and forms a uniform solution. The filler is then added to the solution and dispersed, stirring together. Finally, the mixed matrix membranes are cast by a blade, and its solvent evaporates in the medium at a specific temperature. This method is straightforward and is suitable for all types of inorganic fillers. The concentration of polymer and filler phases is also easily controlled. But the main problem of this method is the accumulation of fillers in the membrane structure. It should be noted that the techniques of homogenizing the solution, such as placing the solution under ultrasound to separate the agglomerated particles from each other, should be done well to prevent the aggregates from clumping. This method is one of the most effective methods to avoid lumps inside the membrane matrix. This method can be used in three ways (Fig. 8). A) Dispersion of the particles in the solvent and stirring sufficiently, and finally adding the polymer to the solution (Fig. $8 \mathrm{~A})$ [200]. B) Dissolving the polymer in the solvent and mixing for a sufficient time, and finally adding the filler particles to the solution (Fig .8B) [54]. C) Dissolving the particles and polymers separately in different solvents and then dispersing in a suitable solvent (Fig. 8C) [201].

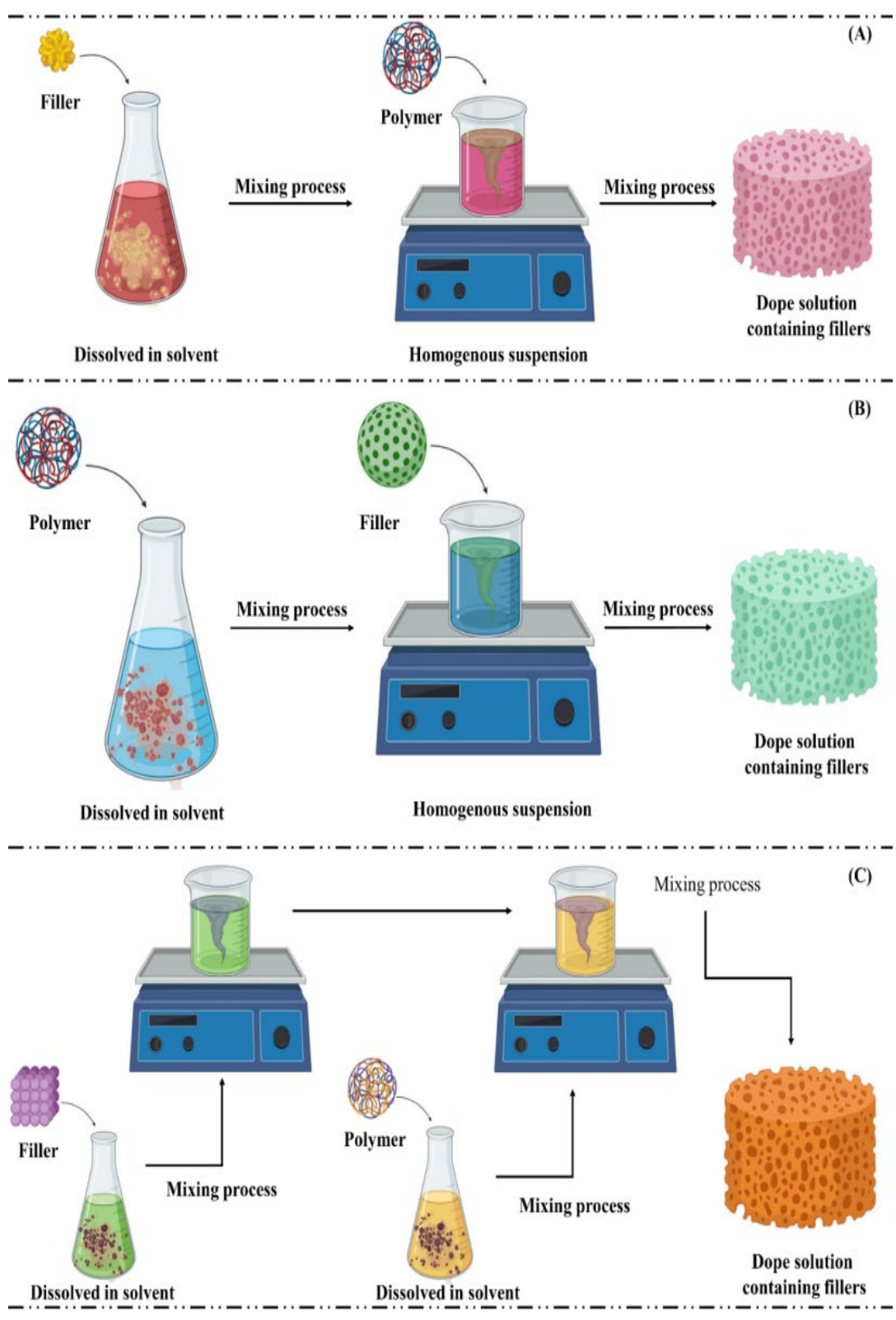

Fig. 8. Different methods of solution mixing method for mixed matrix membranes construction. 


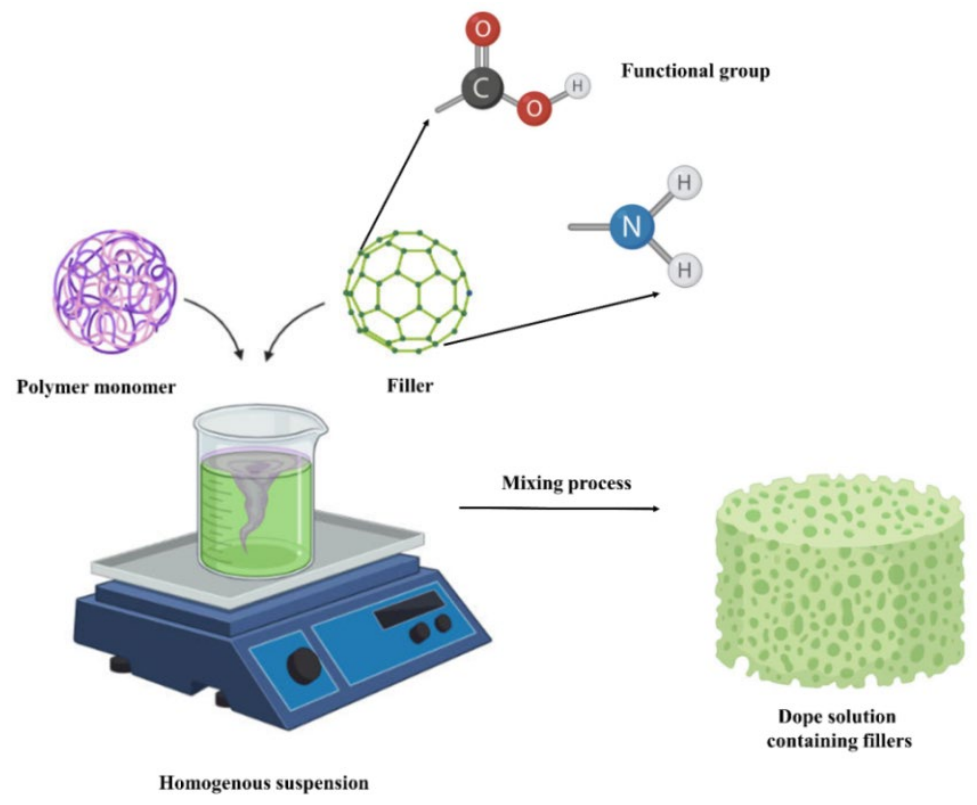

Fig. 9. The Polymerization in situ steps for constructing a mixed matrix membrane.

\subsubsection{Polymerization in situ}

In this method, the filler nanoparticles are mixed well with organic monomers, and then the monomers are polymerized. In this method, some functional groups such as hydroxyl and carboxyl groups on the surface of the filler particles can create free radicals, cations or anions under high radiation energy, plasma, or other methods to initiate the polymerizational reaction of monomers on different surfaces. In the polymerization method, filler nanoparticles with functional groups can bind and bond with the covalent bonds' polymer chain. However, it is challenging to prevent filler nanoparticles' accumulation in membranes formation [54]. The Polymerization in situ steps for constructing a mixed matrix membrane is shown in Fig. 9.

\subsubsection{Sol-gel}

In this method, organic monomers or polymers and the precursor of inorganic nanoparticles are combined in solution. Then the inorganic precursor is hydrolyzed, and the nanoparticles are well-dispersed in the polymer matrix. This method's advantage is the mild reaction conditions (usually room temperature and ambient pressure) and easy control of organic and inorganic components' concentration in the solution. In addition, these particles disperse at the molecular or nanometer level in the membrane and form a homogeneous membrane. The sol-gel steps for constructing a mixed matrix membrane are depicted in Fig. 10.

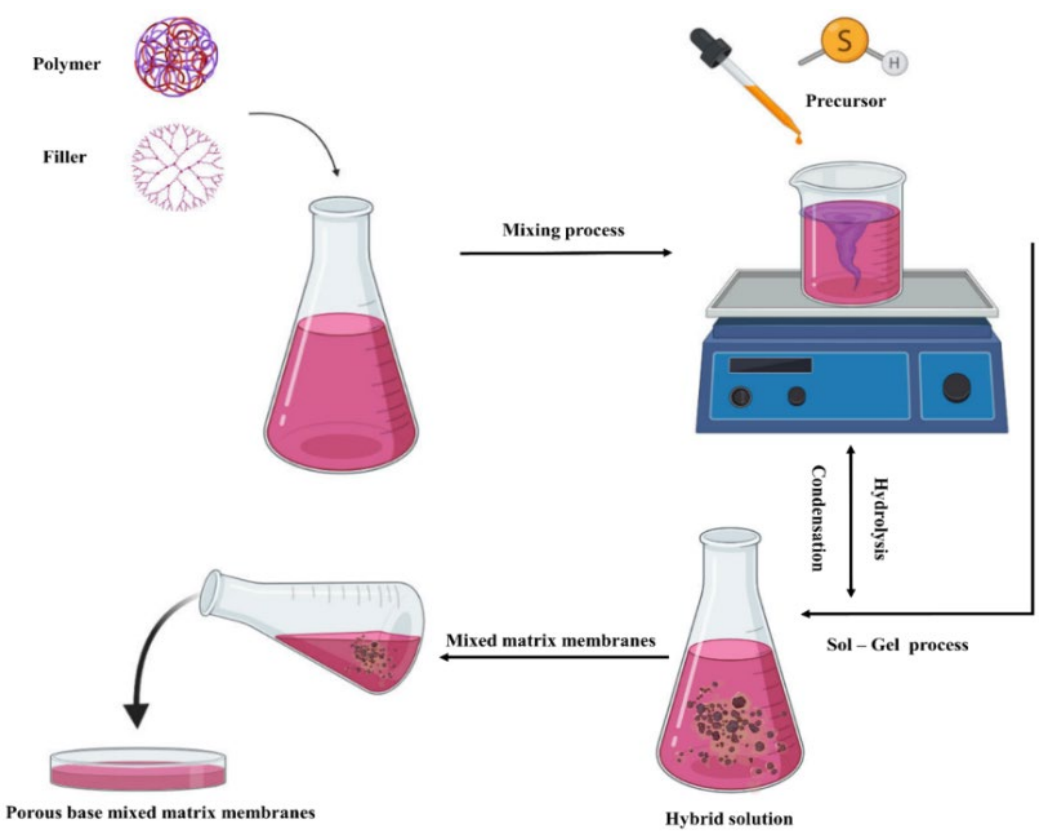

Fig. 10. The Sol-gel steps for constructing a mixed matrix membrane. 


\section{Conclusion}

Proper adhesion and uniform distribution to improve performance are significant challenges in the mixed matrix membranes synthesis. There have been repeated efforts and research, and chemistry and materials have been used to resolve this defect in this context. Although these methods have been somewhat effective, more investigations are still needed in this area. Typically, glassy polymers have good selectivity properties, and rubbery polymers have high permeability properties. Synthesis of polymeric blends with distinct properties is a practical method to increase mixed matrix membranes performance improvement. The preparation of a membrane with homogeneous dispersion of particles is of particular importance. Although chemically compatible with the polymer matrix, particle aggregation is a significant challenge for these membranes, directly affecting the performance of mixed matrix membranes performance. Metal-organic frameworks (MOFs) and zeolites imidazolate frameworks (ZIFs) are efficient nanofillers for mixed matrix membranes synthesis. Cost is another major challenge in the synthesis of combined network membranes. In fact, several network-mixed membranes have been able to cross the Robson exchange line, but the number of economically cost-effective ones is deficient.

\section{References}

[1] I. Salahshoori, D. Nasirian, N. Rashidi, M.K. Hossain, A. Hatami, M. Hassanzadeganroudsari, The effect of silica nanoparticles on polysulfone-polyethylene glycol (PSF/PEG) composite membrane on gas separation and rheological properties of nanocomposites, Polymer Bulletin, (2020).

[2] X. Guo, Z. Qiao, D. Liu, C. Zhong, Mixed-matrix membranes for $\mathrm{CO} 2$ separation: role of the third component, Journal of Materials Chemistry A, 7 (2019) 24738-24759.

[3] A. Hatami, I. Salahshoori, N. Rashidi, D. Nasirian, The effect of ZIF90 particle in Pebax/Psf composite membrane on the transport properties of $\mathrm{CO}_{2}, \mathrm{CH}_{4}$ and $\mathrm{N}_{2}$ gases by Molecular Dynamics Simulation method, Chinese Journal of Chemical Engineering, 28 (2020) 2267-2284

[4] D. Paul, D. Kemp, The diffusion time lag in polymer membranes containing adsorptive fillers, Journal of Polymer Science: Polymer Symposia, Wiley Online Library, 1973, pp. 79-93.

[5] Y. Yuan, Z. Qiao, J. Xu, J. Wang, S. Zhao, X. Cao, Z. Wang, M.D. Guiver, Mixed matrix membranes for $\mathrm{CO}_{2}$ separations by incorporating microporous polymer framework fillers with aminerich nanochannels, Journal of Membrane Science, 620 (2021) 118923.

[6] H. Liang, C. Zou, W. Tang, Development of novel polyether sulfone mixed matrix membranes to enhance antifouling and sustainability: Treatment of oil sands produced water (OSPW), Journal of the Taiwan Institute of Chemical Engineers, (2021).

[7] E. Abdulkarem, Y. Ibrahim, M. Kumar, H.A. Arafat, V. Naddeo, F. Banat, S.W. Hasan, Polyvinylidene fluoride (PVDF) $-\alpha$-zirconium phosphate $(\alpha-\mathrm{ZrP})$ nanoparticles based mixed matrix membranes for removal of heavy metal ions, Chemosphere, 267 (2021) 128896.

[8] C.H. Nguyen, C.-C. Fu, D.-Y. Kao, T.T.V. Tran, R.-S. Juang, Adsorption removal of tetracycline from water using poly(vinylidene fluoride)/polyaniline-montmorillonite mixed matrix membranes, Journal of the Taiwan Institute of Chemical Engineers, 112 (2020) 259-270.

[9] M.R. De Guzman, C.K.A. Andra, M.B.M.Y. Ang, G.V.C. Dizon, A.R. Caparanga, S.-H. Huang, K.-R. Lee, Increased performance and antifouling of mixed-matrix membranes of cellulose acetate with hydrophilic nanoparticles of polydopamine-sulfobetaine methacrylate for oil-water separation, Journal of Membrane Science, 620 (2021) 118881.

[10] D. Bastani, N. Esmaeili, M. Asadollahi, Polymeric mixed matrix membranes containing zeolites as a filler for gas separation applications: A review, Journal of Industrial and Engineering Chemistry, 19 (2013) 375-393.

[11] B. Zhang, Q. Yan, G. Chen, C. Yi, S. Qi, B. Yang, Fabrication of mixed matrix membranes with zinc ion loaded titanium dioxide for improved $\mathrm{CO}_{2}$ separation, Separation and Purification Technology, 254 (2021) 117472.

[12] M. Aroon, A. Ismail, T. Matsuura, M. Montazer-Rahmati, Performance studies of mixed matrix membranes for gas separation: A review, Separation and purification Technology, 75 (2010) 229242.

[13] P. Goh, A. Ismail, S. Sanip, B. Ng, M. Aziz, Recent advances of inorganic fillers in mixed matrix membrane for gas separation, Separation and Purification Technology, 81 (2011) 243-264.

[14] W.F. Yong, H. Zhang, Recent advances in polymer blend membranes for gas separation and pervaporation, Progress in Materials Science, 116 (2021) 100713.

[15] J.-T. Chen, C.-C. Shih, Y.-J. Fu, S.-H. Huang, C.-C. Hu, K.-R. Lee, J.-Y. Lai, Zeolite-filled porous mixed matrix membranes for air separation, Industrial \& Engineering Chemistry Research, 53 (2014) 2781-2789.

[16] J. Shen, M. Zhang, G. Liu, K. Guan, W. Jin, Size effects of graphene oxide on mixed matrix membranes for $\mathrm{CO} 2$ separation, AIChE Journal, 62 (2016) 2843-2852.

[17] K.Goh, H.E. Karahan, E. Yang, T.-H. Bae, Graphene-based membranes for $\mathrm{CO}_{2} / \mathrm{CH}_{4}$ separation: Key challenges and perspectives, Applied Sciences, 9 (2019) 2784.

[18] W.K. Setiawan, K.-Y. Chiang, Silica applied as mixed matrix membrane inorganic filler for gas separation: a review, Sustainable Environment Research, 29 (2019) 1-21.

[19] H. Zhang, R. Guo, J. Hou, Z. Wei, X. Li, Mixed-matrix membranes containing carbon nanotubes composite with hydrogel for efficient $\mathrm{CO}_{2}$ separation, ACS applied materials \& interfaces, 8 (2016) 29044-29051.

[20] S. Sanip, A. Ismail, P. Goh, T. Soga, M. Tanemura, H. Yasuhiko, Gas separation properties of functionalized carbon nanotubes mixed matrix membranes, Separation and Purification Technology, 78 (2011) 208-213.

[21] L. Xiang, Y. Pan, G. Zeng, J. Jiang, J. Chen, C. Wang, Preparation of Poly(ether-block-amide)/Attapulgite Mixed Matrix Membranes for CO2/N2 Separation, Journal of Membrane Science, 500 (2015).

[22] J.A. Thompson, J.T. Vaughn, N.A. Brunelli, W.J. Koros, C.W. Jones, S. Nair, Mixed-linker zeolitic imidazolate framework mixed-matrix membranes for aggressive $\mathrm{CO}_{2}$ separation from natural gas, Microporous and Mesoporous Materials, 192 (2014) 43-51.

[23] R. Lin, B.V. Hernandez, L. Ge, Z. Zhu, Metal organic framework based mixed matrix membranes: an overview on filler/polymer interfaces, Journal of Materials Chemistry A, 6 (2018) 293-312.

[24] B. Zhou, Q. Li, Q. Zhang, J. Duan, W. Jin, Sharply promoted $\mathrm{CO}_{2}$ diffusion in a mixed matrix membrane with hierarchical suprananostructured porous coordination polymer filler, Journal of Membrane Science, 597 (2020) 117772.

[25] M.S. Maleh, A. Raisi, Comparison of porous and nonporous filler effect on performance of poly (ether-block-amide) mixed matrix membranes for gas separation applications, Chemical Engineering Research and Design, 147 (2019) 545-560.

[26] K. Duan, J. Wang, Y. Zhang, J. Liu, Covalent organic frameworks (COFs) functionalized mixed matrix membrane for effective $\mathrm{CO}_{2} / \mathrm{N}_{2}$ separation, Journal of Membrane Science, 572 (2019) 588-595.

[27] T.-S. Chung, L.Y. Jiang, Y. Li, S. Kulprathipanja, Mixed matrix membranes (MMMs) comprising organic polymers with dispersed inorganic fillers for gas separation, Progress in polymer science, 32 (2007) 483-507. 
[28] M. Salehi Maleh, A. Raisi, Comparison of porous and nonporous filler effect on performance of poly (ether-block-amide) mixed matrix membranes for gas separation applications, Chemical Engineering Research and Design, 147 (2019) 545-560.

[29] Q. Xin, C. Zhang, Y. Zhang, Q. Liang, L. Zhang, S. Wang, H. Ye, X. Ding, Y. Zhang, Constructing superhydrophobic surface of PES/PES-SiO2 mixed matrix membrane contactors for efficient $\mathrm{SO} 2$ capture, Separation and Purification Technology, 259 (2021) 118222.

[30] M.D. Asl, I. Salahshoori, A. Seyfaee, A. Hatami, A.A. Golbarari, Experimental results and optimization via design of experiment (DOE) of the copper ion recovery from aqueous solutions using emulsion liquid membrane (ELM) method, Desalination and Water Treatment, (2020).

[31] I. Salahshoori, A. Hatami, A. Seyfaee, Investigation of experimental results and D-optimal design of hafnium ion extraction from aqueous system using emulsion liquid membrane technique, Journal of the Iranian Chemical Society, 18 (2021) 87-107.

[32] M.R. Awual, G.E. Eldesoky, T. Yaita, M. Naushad, H. Shiwaku, Z.A. AlOthman, S. Suzuki, Schiff based ligand containing nanocomposite adsorbent for optical copper (II) ions removal from aqueous solutions, Chemical Engineering Journal, 279 (2015) 639647.

[33] S. Bolisetty, M. Peydayesh, R. Mezzenga, Sustainable technologies for water purification from heavy metals: review and analysis, Chemical Society Reviews, 48 (2019) 463-487.

[34] R. Mukherjee, P. Bhunia, S. De, Impact of graphene oxide on removal of heavy metals using mixed matrix membrane, Chemical Engineering Journal, 292 (2016) 284-297.

[35] A. Zirehpour, A. Rahimpour, M. Jahanshahi, M. Peyravi, Mixed matrix membrane application for olive oil wastewater treatment: Process optimization based on Taguchi design method, Journal of Environmental Management, 132 (2014) 113-120.

[36] S. Saqib, S. Rafiq, N. Muhammad, A.L. Khan, A. Mukhtar, S. Ullah, M.H. Nawaz, F. Jamil, C. Zhang, V. Ashokkumar, Sustainable mixed matrix membranes containing porphyrin and polysulfone polymer for acid gas separations, Journal of Hazardous Materials, 411 (2021) 125155.

[37] C. Wang, G. Ren, K. Wei, D. Liu, T. Wu, J. Jiang, J. Qian, Y. Pan, Improved dispersion performance and interfacial compatibility of covalent-grafted MOFs in mixed-matrix membranes for gas separation, Green Chemical Engineering, (2020).

[38] P. Natarajan, B. Sasikumar, S. Elakkiya, G. Arthanareeswaran, A.F. Ismail, W. Youravong, E. Yuliwati, Pillared cloisite $15 \mathrm{~A}$ as an enhancement filler in polysulfone mixed matrix membranes for $\mathrm{CO}_{2} / \mathrm{N}_{2}$ and $\mathrm{O}_{2} / \mathrm{N}_{2}$ gas separation, Journal of Natural Gas Science and Engineering, 86 (2021) 103720.

[39] M. van Essen, L. van den Akker, R. Thür, M. Houben, I.F.J. Vankelecom, Z. Borneman, K. Nijmeijer, The influence of pore aperture, volume and functionality of isoreticular gmelinite zeolitic imidazolate frameworks on the mixed gas $\mathrm{CO} 2 / \mathrm{N} 2$ and $\mathrm{CO} 2 / \mathrm{CH} 4$ separation performance in mixed matrix membranes, Separation and Purification Technology, 260 (2021) 118103.

[40] M. Raouf, R. Abedini, M. Omidkhah, E. Nezhadmoghadam, A favored $\mathrm{CO} 2$ separation over light gases using mixed matrix membrane comprising polysulfone/polyethylene glycol and graphene hydroxyl nanoparticles, Process Safety and Environmental Protection, 133 (2020) 394-407.

[41] H. Taheri Afarani, M. Sadeghi, A. Moheb, E.N. Esfahani, Optimization of the gas separation performance of polyurethanezeolite $3 \mathrm{~A}$ and ZSM-5 mixed matrix membranes using response surface methodology, Chinese Journal of Chemical Engineering, 27 (2019) 110-129.

[42] C. Song, R. Li, Z. Fan, Q. Liu, B. Zhang, Y. Kitamura, CO2/N2 separation performance of Pebax/MIL-101 and Pebax /NH2-MIL101 mixed matrix membranes and intensification via sub-ambient operation, Separation and Purification Technology, 238 (2020) 116500.
[43] A. Jomekian, R.M. Behbahani, T. Mohammadi, A. Kargari, $\mathrm{CO}_{2} / \mathrm{CH}_{4}$ separation by high performance co-casted ZIF-8/Pebax 1657/PES mixed matrix membrane, Journal of Natural Gas Science and Engineering, 31 (2016) 562-574.

[44] H.J. Lee, S.W. Kang, Activated potassium ions as CO2 carriers for PEBAX-5513/KBF4 composite membranes, Separation and Purification Technology, 258 (2021) 117971.

[45] H.R. Amedi, M. Aghajani, Gas separation in mixed matrix membranes based on polyurethane containing SiO2, ZSM-5, and ZIF-8 nanoparticles, Journal of Natural Gas Science and Engineering, 35 (2016) 695-702.

[46] T. Li, W. Zhang, S. Zhai, G. Gao, J. Ding, W. Zhang, Y. Liu, X. Zhao, B. Pan, L. Lv, Efficient removal of nickel(II) from high salinity wastewater by a novel PAA/ZIF-8/PVDF hybrid ultrafiltration membrane, Water Research, 143 (2018) 87-98.

[47] A. Marjani, A.T. Nakhjiri, M. Adimi, H.F. Jirandehi, S. Shirazian, Effect of graphene oxide on modifying polyethersulfone membrane performance and its application in wastewater treatment, Scientific reports, 10 (2020) 1-11.

[48] Y. Yurekli, Removal of heavy metals in wastewater by using zeolite nano-particles impregnated polysulfone membranes, J Hazard Mater, 309 (2016) 53-64.

[49] K.C. Ho, Y.H. Teow, W.L. Ang, A.W. Mohammad, Novel GO/OMWCNTs mixed-matrix membrane with enhanced antifouling property for palm oil mill effluent treatment, Separation and Purification Technology, 177 (2017) 337-349.

[50] M. Amid, N. Nabian, M. Delavar, Fabrication of polycarbonate ultrafiltration mixed matrix membranes including modified halloysite nanotubes and graphene oxide nanosheets for olive oil/water emulsion separation, Separation and Purification Technology, 251 (2020) 117332.

[51] O. Abdalla, M.A. Wahab, A. Abdala, Mixed matrix membranes containing aspartic acid functionalized graphene oxide for enhanced oil-water emulsion separation, Journal of Environmental Chemical Engineering, 8 (2020) 104269.

[52] A. Alammar, S.-H. Park, C.J. Williams, B. Derby, G. Szekely, Oilin-water separation with graphene-based nanocomposite membranes for produced water treatment, Journal of Membrane Science, 603 (2020) 118007.

[53] R.D. Noble, Perspectives on mixed matrix membranes, Journal of membrane science, 378 (2011) 393-397.

[54] H. Cong, M. Radosz, B.F. Towler, Y. Shen, Polymer-inorganic nanocomposite membranes for gas separation, Separation and purification technology, 55 (2007) 281-291.

[55] T.J. Wenzel, Douglas A. skoog, donald M. west, F. james holler, and stanley R. crouch: Fundamentals of analytical chemistry, Springer, 2013.

[56] S. Meshkat, S. Kaliaguine, D. Rodrigue, Mixed matrix membranes based on amine and non-amine MIL-53(Al) in Pebax ${ }^{\circledR}$ MH-1657 for CO2 separation, Separation and Purification Technology, 200 (2018) 177-190.

[57] M. Farnam, H. bin Mukhtar, A. bin Mohd Shariff, A Review on Glassy and Rubbery Polymeric Membranes for Natural Gas Purification, ChemBioEng Reviews, n/a (2021).

[58] H. Joo Kim, H. Raj Pant, J. Hee Kim, N. Jung Choi, C. Sang Kim, Fabrication of multifunctional TiO2-fly ash/polyurethane nanocomposite membrane via electrospinning, Ceramics International, 40 (2014) 3023-3029.

[59] A. Mushtaq, H.B. Mukhtar, A.M. Shariff, Effect of Glass Transition Temperature in Enhanced Polymeric Blend Membranes, Procedia Engineering, 148 (2016) 11-17.

[60] D. Nasirian, I. Salahshoori, M. Sadeghi, N. Rashidi, M. Hassanzadeganroudsari, Investigation of the gas permeability properties from polysulfone/polyethylene glycol composite membrane, Polymer Bulletin, 77 (2020) 5529-5552.

[61] P. Kubica, A. Wolinska-Grabczyk, E. Grabiec, M. Libera, M. Wojtyniak, S. Czajkowska, M. Domański, Gas transport through 
mixed matrix membranes composed of polysulfone and copper terephthalate particles, Microporous and Mesoporous Materials, 235 (2016) $120-134$.

[62] M. Ahmadi, S. Janakiram, Z. Dai, L. Ansaloni, L. Deng, Performance of Mixed Matrix Membranes Containing Porous TwoDimensional (2D) and Three-Dimensional (3D) Fillers for $\mathrm{CO} 2$ Separation: A Review, Membranes, 8 (2018).

[63] M. Valero, B. Zornoza, C. Téllez, J. Coronas, Mixed matrix membranes for gas separation by combination of silica MCM-41 and MOF NH2-MIL-53(Al) in glassy polymers, Microporous and Mesoporous Materials, 192 (2014) 23-28.

[64] L.A. Utracki, Commercial polymer blends, Springer Science \& Business Media2013.

[65] K. Mortensen, Characterization of Polymer Blends Miscibility, Morphology and Interfaces, (2015).

[66] J.A. Covas, L.A. Pessan, A.V. Machado, N.M. Larocca, Polymer blend compatibilization by copolymers and functional polymers, Encyclopedia of Polymer Blends, (2011) 315-356.

[67] Y.S. Lipatov, A. Nesterov, T. Ignatova, D. Nesterov, Effect of polymer-filler surface interactions on the phase separation in polymer blends, Polymer, 43 (2002) 875-880.

[68] M. Folkes, P. Hope, Polymer blends and alloys, Springer 1993.

[69] L.A. Utracki, Compatibilization of polymer blends, the Canadian journal of chemical Engineering, 80 (2002) 1008-1016.

[70] N. Mostofi, H. Nazockdast, H. Mohammadigoushki, Study on morphology and viscoelastic properties of PP/PET/SEBS ternary blend and their fibers, Journal of applied polymer science, 114 (2009) 3737-3743.

[71] Z. Horák, I. Fortelný, J. Kolařík, D. Hlavatá, A. Sikora, Polymer blends, Encyclopedia of Polymer Science and technology, (2002).

[72] P. Shi, R. Schach, E. Munch, H. Montes, F. Lequeux, Glass transition distribution in miscible polymer blends: from calorimetry to rheology, Macromolecules, 46 (2013) 3611-3620.

[73] Y. Yu, K.J. Choi, Crystallization in blends of poly (ethylene terephthalate) and poly (butylene terephthalate), Polymer Engineering \& Science, 37 (1997) 91-95.

[74] P. Maiti, A.K. Dikshit, A.K. Nandi, Glass-transition temperature of poly (vinylidene fluoride)-poly (methyl acrylate) blends: Influence of aging and chain structure, Journal of applied polymer science, 79 (2001) 1541-1548.

[75] L. Messé, R.E. Prud'Homme, Orientation and relaxation study of polystyrene: Polystyrene/poly (phenylene oxide) blends, Journal of Polymer Science Part B: Polymer Physics, 38 (2000) 1405-1415.

[76] W. Dong, M. He, H. Wang, F. Ren, J. Zhang, X. Zhao, Y. Li, PLLA/ABS blends compatibilized by reactive comb polymers: Double Tg depression and significantly improved toughness, ACS Sustainable Chemistry \& Engineering, 3 (2015) 2542-2550.

[77] W.N. Kim, C.M. Burns, Compatibility studies of polystyrenepolybutadiene blends by thermal analysis, Journal of applied polymer science, 32 (1986) 2989-3004.

[78] Y. Shi, Phase behavior of polyamide 6/612 blends, Plastics Engineering (Apr. 2016), (2016).

[79] A. Al-Jabareen, S. Illescas, M.L. Maspoch, O.O. Santana, Effects of composition and transesterification catalysts on the physico-chemical and dynamic properties of PC/PET blends rich in PC, Journal of Materials Science, 45 (2010) 6623-6633.

[80] R.D. Boyd, J.P.S. Badyal, Silent Discharge Treatment of Immiscible Polystyrene/Polycarbonate Polymer Blend Surfaces, Macromolecules, 30 (1997) 3658-3663.

[81] H. Patil, R.V. Tiwari, M.A. Repka, Hot-melt extrusion: from theory to application in pharmaceutical formulation, Aaps Pharmscitech, 17 (2016) 20-42.

[82] L.A. Utracki, C.A. Wilkie, Polymer blends handbook, Kluwer academic publishers Dordrecht2002.

[83] J.-F. Joanny, L. Leibler, Polymer Blends in Solution, Phase Transitions in Soft Condensed Matter, Springer1989, pp. 297-299.
[84] G. Zhu, F. Wang, K. Xu, Q. Gao, Y. Liu, Study on properties of poly (vinyl alcohol)/polyacrylonitrile blend film, Polímeros, 23 (2013) 146-151.

[85] I. Khan, M. Mansha, M.A. Jafar Mazumder, Polymer Blends, in: M.A. Jafar Mazumder, H. Sheardown, A. Al-Ahmed (Eds.) Functional Polymers, Springer International Publishing, Cham, 2019, pp. 513-549.

[86] J.P. Tomba, X. Ye, F. Li, M.A. Winnik, W. Lau, Polymer blend latex films: Miscibility and polymer diffusion studied by energy transfer, Polymer, 49 (2008) 2055-2064.

[87] J. Feng, M.A. Winnik, R.R. Shivers, B. Clubb, Polymer blend latex films: morphology and transparency, Macromolecules, 28 (1995) 7671-7682.

[88] V. A R M, R. C T, M. Khalid, S. Appadu, G. T C S M, Effect of radiation on the mechanical, morphological and thermal properties of HDPE/rPTFE blends, Radiation Physics and Chemistry, 177 (2020) 109190.

[89] T.A. Lin, J.-H. Lin, L. Bao, A study of reusability assessment and thermal behaviors for thermoplastic composite materials after melting process: Polypropylene/ thermoplastic polyurethane blends, Journal of Cleaner Production, 279 (2021) 123473.

[90] S. Saikrishnan, D. Jubinville, C. Tzoganakis, T.H. Mekonnen, Thermo-mechanical degradation of polypropylene (PP) and lowdensity polyethylene (LDPE) blends exposed to simulated recycling, Polymer Degradation and Stability, 182 (2020) 109390.

[91] H. Nie, D. Liu, C. Liu, X. Wang, A. He, Morphology evolution in solution polymerized styrene-butadiene rubber (SSBR) / trans-1,4polyisoprene (TPI) blends: SSBR particle formation, TPI crystal nucleation, growth and polymorphic form, Polymer, 117 (2017) 1116.

[92] J. Yin, H. Tang, Z. Xu, N. Li, Enhanced mechanical strength and performance of sulfonated polysulfone/Tröger's base polymer blend ultrafiltration membrane, Journal of Membrane Science, (2021) 119138.

[93] M. Sadiq, M.M. Hasan Raza, A.K. Singh, S.K. Chaurasia, M. Zulfequar, A. Arya, J. Ali, Dielectric properties and ac conductivity behavior of rGO incorporated PVP-PVA blended polymer nanocomposites films, Materials Today: Proceedings, (2020).

[94] T. Shirahase, S. Akasaka, S. Asai, Organic solvent-free fabrication of mesoporous polymer monolith from miscible PLLA/PMMA blend, Polymer, 203 (2020) 122742.

[95] S.M. Hanson, S. Singh, A. Tabet, K.J. Sastry, M. Barry, C. Wang, Mucoadhesive wafers composed of binary polymer blends for sublingual delivery and preservation of protein vaccines, Journal of Controlled Release, 330 (2021) 427-437.

[96] H. Jiang, Q. Zhao, P. Wang, J. Ma, X. Zhai, Improved separation and antifouling properties of PVDF gravity-driven membranes by blending with amphiphilic multi-arms polymer PPG-Si-PEG, Journal of Membrane Science, 588 (2019) 117148.

[97] J. Khanjani, S. Pazokifard, M.J. Zohuriaan-Mehr, Improving dirt pickup resistance in waterborne coatings using latex blends of acrylic/PDMS polymers, Progress in Organic Coatings, 102 (2017) 151-166.

[98] C.F. Lee, The properties of core-shell composite polymer latex.: Effect of heating on the morphology and physical properties of PMMA/PS core-shell composite latex and the polymer blends, Polymer, 41 (2000) 1337-1344.

[99] C. Wang, F. Chu, C. Graillat, A. Guyot, C. Gauthier, J.P. Chapel, Hybrid polymer latexes: acrylics-polyurethane from miniemulsion polymerization: properties of hybrid latexes versus blends, Polymer, 46 (2005) 1113-1124.

[100] L.M. Robeson, The upper bound revisited, Journal of membrane science, 320 (2008) 390-400.

[101] G. Kapantaidakis, G. Koops, M. Wessling, Preparation and characterization of gas separation hollow fiber membranes based on polyethersulfone-polyimide miscible blends, Desalination, 145 (2002) 353-357. 
[102] R.M. Lilleby Helberg, Z. Dai, L. Ansaloni, L. Deng, PVA/PVP blend polymer matrix for hosting carriers in facilitated transport membranes: Synergistic enhancement of $\mathrm{CO} 2$ separation performance, Green Energy \& Environment, 5 (2020) 59-68.

[103] J. Sánchez-Laínez, A. Pardillos-Ruiz, M. Carta, R. Malpass-Evans, N.B. McKeown, C. Téllez, J. Coronas, Polymer engineering by blending PIM-1 and 6FDA-DAM for ZIF-8 containing mixed matrix membranes applied to $\mathrm{CO} 2$ separations, Separation and Purification Technology, 224 (2019) 456-462.

[104] M. Kheirtalab, R. Abedini, M. Ghorbani, A novel ternary mixed matrix membrane comprising polyvinyl alcohol (PVA)-modified poly (ether-block-amide)(Pebax $\left.{ }^{\circledR} 1657\right) /$ graphene oxide nanoparticles for $\mathrm{CO} 2$ separation, Process Safety and Environmental Protection, 144 (2020) 208-224.

[105] H. Rajati, A.H. Navarchian, S. Tangestaninejad, Preparation and characterization of mixed matrix membranes based on Matrimid/PVDF blend and MIL-101(Cr) as filler for $\mathrm{CO} 2 / \mathrm{CH} 4$ separation, Chemical Engineering Science, 185 (2018) 92-104.

[106] H. Shin, W.S. Chi, S. Bae, J.H. Kim, J. Kim, High-performance thin PVC-POEM/ZIF-8 mixed matrix membranes on alumina supports for $\mathrm{CO} 2 / \mathrm{CH} 4$ separation, Journal of Industrial and Engineering Chemistry, 53 (2017) 127-133.

[107] Y. Mansourpanah, S.S. Madaeni, M. Adeli, A. Rahimpour, A. Farhadian, Surface modification and preparation of nanofiltration membrane from polyethersulfone/polyimide blend-Use of a new material (polyethyleneglycol-triazine), Journal of Applied Polymer Science, 112 (2009) 2888-2895.

[108] C. Hegde, A.M. Isloor, M. Padaki, H.-K. Fun, Synthesis and performance characterization of PS-PPEES nanoporous membranes with nonwoven porous support, Arabian Journal of Chemistry, 6 (2013) 319-326.

[109] B.M. Ganesh, A.M. Isloor, M. Padaki, Preparation and characterization of polysulfone and modified poly isobutylene-altmaleic anhydride blend NF membrane, Desalination, 287 (2012) 103-108.

[110] Y. Meng, L. Shu, L.-H. Xie, M. Zhao, T. Liu, J.-R. Li, High performance nanofiltration in BUT-8(A)/PDDA mixed matrix membrane fabricated by spin-assisted layer-by-layer assembly, Journal of the Taiwan Institute of Chemical Engineers, 115 (2020) 331-338.

[111] H. An, K.Y. Cho, S. Back, X.H. Do, J.-D. Jeon, H.K. Lee, K.-Y. Baek, J.S. Lee, The significance of the interfacial interaction in mixed matrix membranes for enhanced propylene/propane separation performance and plasticization resistance, Separation and Purification Technology, 261 (2021) 118279.

[112] Q. Zhang, H. Li, S. Chen, J. Duan, W. Jin, Mixed-matrix membranes with soluble porous organic molecular cage for highly efficient C3H6/C3H8 separation, Journal of Membrane Science, 611 (2020) 118288.

[113] Q.V. Ly, C.N. Matindi, A.T. Kuvarega, Q.V. Le, V.S. Tran, Y. Hu, J. Li, Organic fouling assessment of novel PES/SPSf/Double layered hydroxide mixed matrix membrane for water treatment application, Journal of Water Process Engineering, 37 (2020) 101526.

[114] P. Tremblay, M.M. Savard, J. Vermette, R. Paquin, Gas permeability, diffusivity and solubility of nitrogen, helium, methane, carbon dioxide and formaldehyde in dense polymeric membranes using a new on-line permeation apparatus, Journal of Membrane Science, 282 (2006) 245-256.

[115] M.A. Semsarzadeh, B. Ghalei, Characterization and gas permeability of polyurethane and polyvinyl acetate blend membranes with polyethylene oxide-polypropylene oxide block copolymer, Journal of Membrane Science, 401-402 (2012) 97-108.

[116] S. Salehi Shahrabi, H.R. Mortaheb, J. Barzin, M.R. Ehsani, Pervaporative performance of a PDMS/blended PES composite membrane for removal of toluene from water, Desalination, 287 (2012) 281-289.
[117] S.J. Lue, J.S. Ou, C.H. Kuo, H.Y. Chen, T.-H. Yang, Pervaporative separation of azeotropic methanol/toluene mixtures in polyurethanepoly(dimethylsiloxane) (PU-PDMS) blend membranes: Correlation with sorption and diffusion behaviors in a binary solution system, Journal of Membrane Science, 347 (2010) 108-115.

[118] D. Zavastin, I. Cretescu, M. Bezdadea, M. Bourceanu, M. Drăgan, G. Lisa, I. Mangalagiu, V. Vasić, J. Savić, Preparation, characterization and applicability of cellulose acetate-polyurethane blend membrane in separation techniques, Colloids and Surfaces A: Physicochemical and Engineering Aspects, 370 (2010) 120-128.

[119] A.L. Ahmad, W.Y. Pang, Z.M.H. Mohd Shafie, N.D. Zaulkiflee, $\mathrm{PES} / \mathrm{PVP} / \mathrm{TiO} 2$ mixed matrix hollow fiber membrane with antifouling properties for humic acid removal, Journal of Water Process Engineering, 31 (2019) 100827.

[120] R. Mahajan, W.J. Koros, Factors Controlling Successful Formation of Mixed-Matrix Gas Separation Materials, Industrial \& Engineering Chemistry Research, 39 (2000) 2692-2696.

[121] R. Mahajan, R. Burns, M. Schaeffer, W.J. Koros, Challenges in forming successful mixed matrix membranes with rigid polymeric materials, Journal of Applied Polymer Science, 86 (2002) 881-890.

[122] C.A. Scholes, G.W. Stevens, S.E. Kentish, Membrane gas separation applications in natural gas processing, Fuel, 96 (2012) 15 28.

[123] D. Sen, H. Kalipcilar, L. Yilmaz, Development of zeolite filled polycarbonate mixed matrix gas separation membranes, Desalination, 200 (2006) 222-224.

[124] J. Caro, M. Noack, P. Kölsch, Zeolite membranes: from the laboratory scale to technical applications, Adsorption, 11 (2005) 215-227.

[125] P.S. Goh, A.F. Ismail, S.M. Sanip, B.C. Ng, M. Aziz, Recent advances of inorganic fillers in mixed matrix membrane for gas separation, Separation and Purification Technology, 81 (2011) 243264.

[126] M. Vinoba, M. Bhagiyalakshmi, Y. Alqaheem, A.A. Alomair, A. Pérez, M.S. Rana, Recent progress of fillers in mixed matrix membranes for $\mathrm{CO} 2$ separation: A review, Separation and Purification Technology, 188 (2017) 431-450.

[127] S. Husain, W.J. Koros, Mixed matrix hollow fiber membranes made with modified HSSZ-13 zeolite in polyetherimide polymer matrix for gas separation, Journal of Membrane Science, 288 (2007) 195-207.

[128] G. Majano, S. Mintova, O. Ovsitser, B. Mihailova, T. Bein, Zeolite Beta nanosized assemblies, Microporous and mesoporous materials, 80 (2005) 227-235.

[129] L. Tosheva, V.P. Valtchev, Nanozeolites: synthesis, crystallization mechanism, and applications, Chemistry of materials, 17 (2005) 2494-2513.

[130] I. Khan, K. Saeed, I. Khan, Nanoparticles: Properties, applications and toxicities, Arabian journal of chemistry, 12 (2019) 908-931.

[131] J. Jeevanandam, A. Barhoum, Y.S. Chan, A. Dufresne, M.K. Danquah, Review on nanoparticles and nanostructured materials: history, sources, toxicity and regulations, Beilstein journal of nanotechnology, 9 (2018) 1050-1074.

[132] C. Burda, X. Chen, R. Narayanan, M.A. El-Sayed, Chemistry and Properties of Nanocrystals of Different Shapes, Chemical Reviews, 105 (2005) 1025-1102.

[133] L. Marinescu, D. Ficai, O. Oprea, A. Marin, A. Ficai, E. Andronescu, A.-M. Holban, Optimized Synthesis Approaches of Metal Nanoparticles with Antimicrobial Applications, Journal of Nanomaterials, 2020 (2020).

[134] S. Iravani, H. Korbekandi, S.V. Mirmohammadi, B. Zolfaghari, Synthesis of silver nanoparticles: chemical, physical and biological methods, Research in pharmaceutical sciences, 9 (2014) 385.

[135] A. Aqel, K.M. Abou El-Nour, R.A. Ammar, A. Al-Warthan, Carbon nanotubes, science and technology part (I) structure, synthesis and characterisation, Arabian Journal of Chemistry, 5 (2012) 1-23. 
[136] N.G. Sahoo, S. Rana, J.W. Cho, L. Li, S.H. Chan, Polymer nanocomposites based on functionalized carbon nanotubes, Progress in polymer science, 35 (2010) 837-867.

[137] P.-C. Ma, N.A. Siddiqui, G. Marom, J.-K. Kim, Dispersion and functionalization of carbon nanotubes for polymer-based nanocomposites: a review, Composites Part A: Applied Science and Manufacturing, 41 (2010) 1345-1367.

[138] K. Yang, Z. Yi, Q. Jing, R. Yue, W. Jiang, D. Lin, Sonicationassisted dispersion of carbon nanotubes in aqueous solutions of the anionic surfactant SDBS: The role of sonication energy, Chinese science bulletin, 58 (2013) 2082-2090.

[139] R. Rastogi, R. Kaushal, S. Tripathi, A.L. Sharma, I. Kaur, L.M. Bharadwaj, Comparative study of carbon nanotube dispersion using surfactants, Journal of colloid and interface science, 328 (2008) 421428.

[140] M.N. Nejad, M. Asghari, M. Afsari, Investigation of carbon nanotubes in mixed matrix membranes for gas separation: a review, ChemBioEng Reviews, 3 (2016) 276-298.

[141] A.K. Geim, K.S. Novoselov, The rise of graphene, Nanoscience and technology: a collection of reviews from nature journals, World Scientific2010, pp. 11-19.

[142] J. Song, X. Wang, C.-T. Chang, Preparation and Characterization of Graphene Oxide, Journal of Nanomaterials, 2014 (2014) 276143.

[143] S. Wang, Y. Xie, G. He, Q. Xin, J. Zhang, L. Yang, Y. Li, H. Wu, Y. Zhang, M.D. Guiver, Graphene oxide membranes with heterogeneous nanodomains for efficient $\mathrm{CO} 2$ separations, Angewandte Chemie International Edition, 56 (2017) 14246-14251.

[144] M.S.A. Bhuyan, M.N. Uddin, M.M. Islam, F.A. Bipasha, S.S. Hossain, Synthesis of graphene, International Nano Letters, 6 (2016) 65-83.

[145] D. Chen, L. Tang, J. Li, Graphene-based materials in electrochemistry, Chemical Society Reviews, 39 (2010) 3157-3180.

[146] K. Parvez, Z.-S. Wu, R. Li, X. Liu, R. Graf, X. Feng, K. Müllen, Exfoliation of Graphite into Graphene in Aqueous Solutions of Inorganic Salts, Journal of the American Chemical Society, 136 (2014) 6083-6091.

[147] M.S. Alhumaimess, Metal-Organic Frameworks and their Catalytic Applications, Journal of Saudi Chemical Society, (2020).

[148] S.T. Meek, J.A. Greathouse, M.D. Allendorf, Metal-Organic Frameworks: A Rapidly Growing Class of Versatile Nanoporous Materials, Advanced Materials, 23 (2011) 249-267.

[149] S.R. Venna, M.A. Carreon, Highly permeable zeolite imidazolate framework- 8 membranes for $\mathrm{CO} / \mathrm{CH} 4$ separation, Journal of the American Chemical Society, 132 (2010) 76-78.

[150] N. Keser, Production and performance evaluation of ZIF-8 based binary and ternary mixed matrix gas separation membranes, 2012 .

[151] R. Mallada, Hydrothermal Synthesis of Zeolite, in: E. Drioli, L. Giorno (Eds.) Encyclopedia of Membranes, Springer Berlin Heidelberg, Berlin, Heidelberg, 2015, pp. 1-2.

[152] Y. Li, W. Yang, Microwave synthesis of zeolite membranes: A review, Journal of Membrane Science, 316 (2008) 3-17.

[153] S. Manafi, S. Joughehdoust, Production of zeolite using different methods, 2008.

[154] D.M. Mattox, Physical vapor deposition (PVD) processes, Metal Finishing, 100 (2002) 394-408.

[155] Y. Zhang, K.J. Balkus, I.H. Musselman, J.P. Ferraris, Mixed-matrix membranes composed of Matrimid $\mathbb{}($ and mesoporous ZSM-5 nanoparticles, Journal of Membrane Science, 325 (2008) 28-39.

[156] X. Zhan, J. Lu, T. Tan, J. Li, Mixed matrix membranes with HF acid etched ZSM-5 for ethanol/water separation: Preparation and pervaporation performance, Applied Surface Science, 259 (2012) $547-556$.

[157] M. Vatani, A. Raisi, G. Pazuki, Three-component mixed matrix membrane containing [Hmim][PF6] ionic liquid and ZSM-5 nanoparticles based on poly (ether-block-amide) for the pervaporation process, Journal of Molecular Liquids, 277 (2019) 471-480.
[158] M. Vatani, A. Raisi, G. Pazuki, Mixed matrix membrane of ZSM5/poly (ether-block-amide)/polyethersulfone for pervaporation separation of ethyl acetate from aqueous solution, Microporous and Mesoporous Materials, 263 (2018) 257-267.

[159] M. Asghari, M. Mosadegh, H. Riasat Harami, Supported PEBAzeolite 13X nano-composite membranes for gas separation: Preparation, characterization and molecular dynamics simulation, Chemical Engineering Science, 187 (2018) 67-78.

[160] N. Bryan, E. Lasseuguette, M. van Dalen, N. Permogorov, A. Amieiro, S. Brandani, M.-C. Ferrari, Development of Mixed Matrix Membranes Containing Zeolites for Post-combustion Carbon Capture, Energy Procedia, 63 (2014) 160-166.

[161] J. Ahmad, M.B. Hägg, Effect of zeolite preheat treatment and membrane post heat treatment on the performance of polyvinyl acetate/zeolite 4A mixed matrix membrane, Separation and Purification Technology, 115 (2013) 163-171.

[162] T. Khosravi, S. Mosleh, O. Bakhtiari, T. Mohammadi, Mixed matrix membranes of Matrimid 5218 loaded with zeolite 4A for pervaporation separation of water-isopropanol mixtures, Chemical Engineering Research and Design, 90 (2012) 2353-2363.

[163] A. Mahmoudi, M. Asghari, V. Zargar, $\mathrm{CO} 2 / \mathrm{CH} 4$ separation through a novel commercializable three-phase PEBA/PEG/NaX nanocomposite membrane, Journal of Industrial and Engineering Chemistry, 23 (2015) 238-242.

[164] K. Zarshenas, A. Raisi, A. Aroujalian, Mixed matrix membrane of nano-zeolite $\mathrm{NaX} /$ poly (ether-block-amide) for gas separation applications, Journal of Membrane Science, 510 (2016) 270-283.

[165] M. Dehghani, M. Asghari, A.H. Mohammadi, M. Mokhtari, Molecular simulation and Monte Carlo study of structural-transportproperties of PEBA-MFI zeolite mixed matrix membranes for $\mathrm{CO} 2$, CH4 and N2 separation, Computers \& Chemical Engineering, 103 (2017) 12-22.

[166] Y. Gou, L. Xiao, Y. Yang, X. Guo, F. Zhang, W. Zhu, Q. Xiao, Incorporation of open-pore MFI zeolite nanosheets in polydimethylsiloxane (PDMS) to isomer-selective mixed matrix membranes, Microporous and Mesoporous Materials, 315 (2021) 110930.

[167] N.N.R. Ahmad, C.P. Leo, A.L. Ahmad, Effects of solvent and ionic liquid properties on ionic liquid enhanced polysulfone/SAPO-34 mixed matrix membrane for $\mathrm{CO} 2$ removal, Microporous and Mesoporous Materials, 283 (2019) 64-72.

[168] G. Sodeifian, M. Raji, M. Asghari, M. Rezakazemi, A. Dashti, Polyurethane-SAPO-34 mixed matrix membrane for $\mathrm{CO} / \mathrm{CH} 4$ and $\mathrm{CO} 2 / \mathrm{N} 2$ separation, Chinese Journal of Chemical Engineering, 27 (2019) 322-334.

[169] J. Kim, Q. Fu, K. Xie, J.M.P. Scofield, S.E. Kentish, G.G. Qiao, $\mathrm{CO} 2$ separation using surface-functionalized $\mathrm{SiO} 2$ nanoparticles incorporated ultra-thin film composite mixed matrix membranes for post-combustion carbon capture, Journal of Membrane Science, 515 (2016) 54-62.

[170] A. Ghadimi, T. Mohammadi, N. Kasiri, A Novel Chemical Surface Modification for the Fabrication of PEBA/SiO2 Nanocomposite Membranes To Separate CO2 from Syngas and Natural Gas Streams, Industrial \& Engineering Chemistry Research, 53 (2014) 1747617486.

[171] S. Hassanajili, M. Khademi, P. Keshavarz, Influence of various types of silica nanoparticles on permeation properties of polyurethane/silica mixed matrix membranes, Journal of Membrane Science, 453 (2014) 369-383.

[172] M. Obaid, G.M.K. Tolba, M. Motlak, O.A. Fadali, K.A. Khalil, A.A. Almajid, B. Kim, N.A.M. Barakat, Effective polysulfoneamorphous $\mathrm{SiO} 2 \mathrm{NPs}$ electrospun nanofiber membrane for high flux oil/water separation, Chemical Engineering Journal, 279 (2015) 631638.

[173] M.B. Alkindy, V. Naddeo, F. Banat, S.W. Hasan, Synthesis of polyethersulfone (PES)/GO-SiO2 mixed matrix membranes for oily 
wastewater treatment, Water Science and Technology, 81 (2020) 1354-1364.

[174] Q. Liu, N. Xu, L. Fan, A. Ding, Q. Dong, Polyacrylonitrile (PAN)/TiO2 mixed matrix membrane synthesis by thermally induced self-crosslinking for thermal and organic-solvent resistant filtration, Chemical Engineering Science, 228 (2020) 115993.

[175] H. Zhu, J. Yuan, J. Zhao, G. Liu, W. Jin, Enhanced CO2/N2 separation performance by using dopamine/polyethyleneiminegrafted $\mathrm{TiO} 2$ nanoparticles filled PEBA mixed-matrix membranes, Separation and Purification Technology, 214 (2019) 78-86.

[176] Y.H. Teow, B.S. Ooi, A.L. Ahmad, Study on PVDF-TiO2 mixedmatrix membrane behaviour towards humic acid adsorption, Journal of Water Process Engineering, 15 (2017) 99-106.

[177] Z. Farashi, S. Azizi, M. Rezaei-Dasht Arzhandi, Z. Noroozi, N. Azizi, Improving $\mathrm{CO} 2 / \mathrm{CH} 4$ separation efficiency of Pebax-1657 membrane by adding $\mathrm{Al} 2 \mathrm{O} 3$ nanoparticles in its matrix, Journal of Natural Gas Science and Engineering, 72 (2019) 103019.

[178] L. Wang, X. Song, T. Wang, S. Wang, Z. Wang, C. Gao, Fabrication and characterization of polyethersulfone/carbon nanotubes (PES/CNTs) based mixed matrix membranes (MMMs) for nanofiltration application, Applied Surface Science, 330 (2015) 118125.

[179] Z. Raeisi, A. Moheb, M.N. Arani, M. Sadeghi, Non-covalentlyfunctionalized CNTs incorporating poly(vinyl alcohol) mixed matrix membranes for pervaporation separation of water-isopropanol mixtures, Chemical Engineering Research and Design, 167 (2021) 157-168

[180] S. Zhang, Q. Wang, D. Li, F. Ran, Single-walled carbon nanotubes grafted with dextran as additive to improve separation performance of polymer membranes, Separation and Purification Technology, 254 (2021) 117584.

[181] G.N.B. Baroña, M. Choi, B. Jung, High permeate flux of PVA/PSf thin film composite nanofiltration membrane with aluminosilicate single-walled nanotubes, Journal of Colloid and Interface Science, 386 (2012) 189-197.

[182] J. Yin, G. Zhu, B. Deng, Multi-walled carbon nanotubes (MWNTs)/polysulfone (PSU) mixed matrix hollow fiber membranes for enhanced water treatment, Journal of Membrane Science, 437 (2013) 237-248.

[183] H. Sun, W. Gao, Y. Zhang, X. Cao, S. Bao, P. Li, Z. Kang, Q.J. Niu, Bis(phenyl)fluorene-based polymer of intrinsic microporosity/functionalized multi-walled carbon nanotubes mixed matrix membranes for enhanced $\mathrm{CO} 2$ separation performance, Reactive and Functional Polymers, 147 (2020) 104465.

[184] C.Y. Tang, A.K. Zulhairun, T.W. Wong, S. Alireza, M.S.A. Marzuki, A.F. Ismail, Water transport properties of boron nitride nanosheets mixed matrix membranes for humic acid removal, Heliyon, 5 (2019) e01142.

[185] L.M. Camacho, T.A. Pinion, S.O. Olatunji, Behavior of mixedmatrix graphene oxide - Polysulfone membranes in the process of direct contact membrane distillation, Separation and Purification Technology, 240 (2020) 116645.

[186] H. Namdar, A. Akbari, R. Yegani, H. Roghani-Mamaqani, Influence of aspartic acid functionalized graphene oxide presence in polyvinylchloride mixed matrix membranes on chromium removal from aqueous feed containing humic acid, Journal of Environmental Chemical Engineering, 9 (2021) 104685.

[187] K. Sainath, A. Modi, J. Bellare, CO2/CH4 mixed gas separation using graphene oxide nanosheets embedded hollow fiber membranes: Evaluating effect of filler concentration on performance, Chemical Engineering Journal Advances, 5 (2021) 100074.

[188] S. Ashtiani, M. Khoshnamvand, D. Bouša, J. Šturala, Z. Sofer, A. Shaliutina-Kolešová, D. Gardenö, K. Friess, Surface and interface engineering in $\mathrm{CO} 2$-philic based UiO-66-NH2-PEI mixed matrix membranes via covalently bridging PVP for effective hydrogen purification, International Journal of Hydrogen Energy, 46 (2021) 5449-5458.

[189] Y.M. Xu, S. Japip, T.-S. Chung, Mixed matrix membranes with nano-sized functional UiO-66-type MOFs embedded in 6FDA$\mathrm{HAB} / \mathrm{DABA}$ polyimide for dehydration of C1-C3 alcohols via pervaporation, Journal of Membrane Science, 549 (2018) 217-226.

[190] M. Mubashir, Y. Yin fong, C.T. Leng, L.K. Keong, N. Jusoh, Study on the effect of process parameters on $\mathrm{CO} 2 / \mathrm{CH} 4$ binary gas separation performance over NH2-MIL-53(Al)/cellulose acetate hollow fiber mixed matrix membrane, Polymer Testing, 81 (2020) 106223.

[191] J. Ma, S. Li, G. Wu, S. Wang, X. Guo, L. Wang, X. Wang, J. Li, L. Chen, Preparation of mixed-matrix membranes from metal organic framework (MIL-53) and poly (vinylidene fluoride) for use in determination of sulfonylurea herbicides in aqueous environments by high performance liquid chromatography, Journal of Colloid and Interface Science, 553 (2019) 834-844.

[192] X. Dong, Q. Liu, A. Huang, Highly permselective MIL68( $\mathrm{Al})$ /matrimid mixed matrix membranes for $\mathrm{CO} 2 / \mathrm{CH} 4$ separation, Journal of Applied Polymer Science, 133 (2016).

[193] M. Khdhayyer, A.F. Bushell, P.M. Budd, M.P. Attfield, D. Jiang, A.D. Burrows, E. Esposito, P. Bernardo, M. Monteleone, A. Fuoco, G. Clarizia, F. Bazzarelli, A. Gordano, J.C. Jansen, Mixed matrix membranes based on MIL-101 metal-organic frameworks in polymer of intrinsic microporosity PIM-1, Separation and Purification Technology, 212 (2019) 545-554.

[194] M. Waqas Anjum, B. Bueken, D. De Vos, I.F.J. Vankelecom, MIL125(Ti) based mixed matrix membranes for $\mathrm{CO} 2$ separation from CH4 and N2, Journal of Membrane Science, 502 (2016) 21-28.

[195] J. Gao, H. Mao, H. Jin, C. Chen, A. Feldhoff, Y. Li, Functionalized ZIF-7/Pebax ${ }^{\circledR} 2533$ mixed matrix membranes for $\mathrm{CO} 2 / \mathrm{N} 2$ separation, Microporous and Mesoporous Materials, 297 (2020) 110030.

[196] X. Li, S. Yu, K. Li, C. Ma, J. Zhang, H. Li, X. Chang, L. Zhu, Q. Xue, Enhanced gas separation performance of Pebax mixed matrix membranes by incorporating ZIF-8 in situ inserted by multiwalled carbon nanotubes, Separation and Purification Technology, 248 (2020) 117080 .

[197] A. Ehsani, M. Pakizeh, Synthesis, characterization and gas permeation study of ZIF-11/Pebax ${ }^{\circledR} 2533$ mixed matrix membranes, Journal of the Taiwan Institute of Chemical Engineers, 66 (2016) 414-423.

[198] F. Moghadam, T.H. Lee, I. Park, H.B. Park, Thermally annealed polyimide-based mixed matrix membrane containing ZIF-67 decorated porous graphene oxide nanosheets with enhanced propylene/propane selectivity, Journal of Membrane Science, 603 (2020) 118019.

[199] Q. Zhang, S. Luo, J.R. Weidman, R. Guo, Preparation and gas separation performance of mixed-matrix membranes based on triptycene-containing polyimide and zeolite imidazole framework (ZIF-90), Polymer, 131 (2017) 209-216.

[200] L.Y. Jiang, T.S. Chung, C. Cao, Z. Huang, S. Kulprathipanja, Fundamental understanding of nano-sized zeolite distribution in the formation of the mixed matrix single-and dual-layer asymmetric hollow fiber membranes, Journal of membrane science, 252 (2005) 89-100.

[201] S. Husain, W.J. Koros, Mixed matrix hollow fiber membranes made with modified HSSZ-13 zeolite in polyetherimide polymer matrix for gas separation, Journal of Membrane Science, 288 (2007) 195-207. 